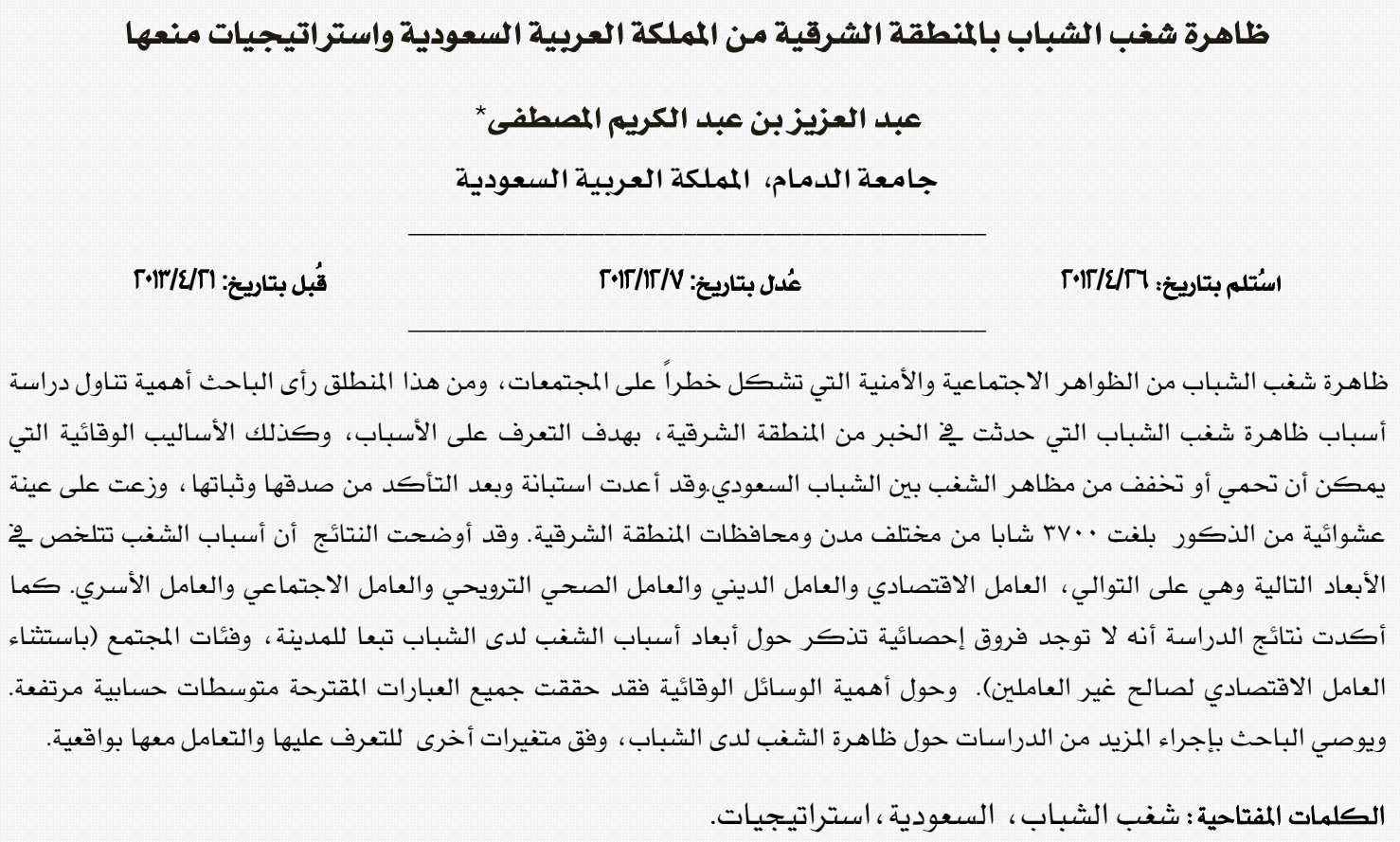

\title{
The Phenomenon of Rioting among the Youth in the Eastern Province in Saudi A rabia and the Prevention Strategies
}

\author{
Aziz A. Mustafa* \\ Aldammam University, Kingdom of Saudi Arabia
}

The phenomenon of rioting among youth is a social and security problem which constitutes a threatening danger to societies. The present study aimed to identify the underlying causes of rioting in Alkhobar and the preventive measures that can be taken to stop the manifestations of unrest among youth in future. Questionnaires, whose validity and reliability were properly confirmed, were distributed among randomly-chosen $(n=3700)$ youth from all the Eastern Province cities. The results revealed that the causes of rioting among Saudi youths are dueto many factors like economic, religious, health, recreational, social and familial. The results also showed that there was no significant difference in the dimensions of the causes of unrest among the youth in respect to the city, community or group, with the exception of the economic factor which showed a tilt towards the unemployed. Regarding the importance of preventive measures and strategies to deal with these problems, many possibilities were presented to the participants who responded favorably to such a propositions. More research in this phenomenon is highly needed, taking into consideration other variables in order to identify them more realistically.

Keywords: youth rioting, Saudi A rabia, Strategies.

*aziz89@hotmail.com 
كمرض الجتماعي يتنافى مع القيم القيم الأخلاقية

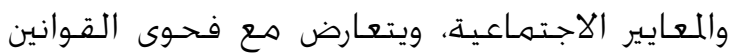

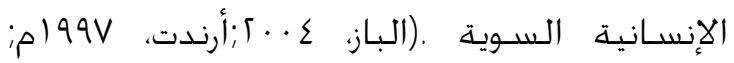

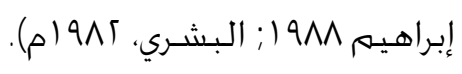

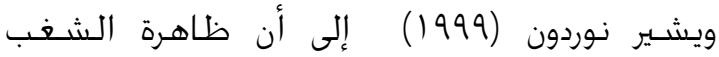

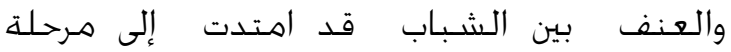

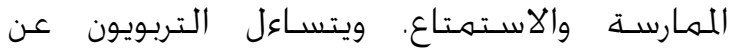

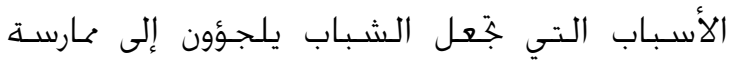

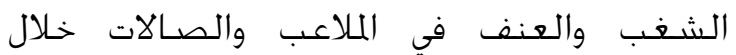

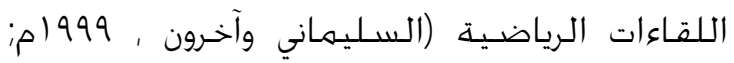

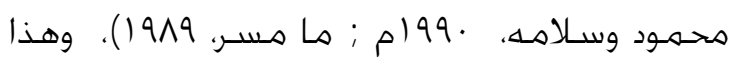

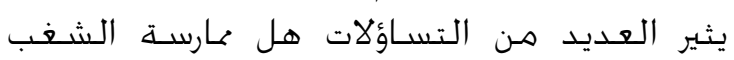

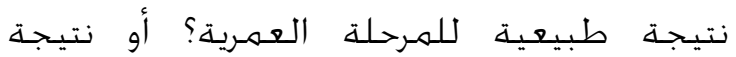

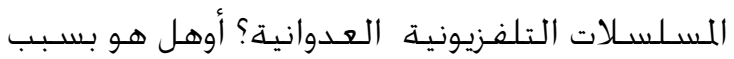

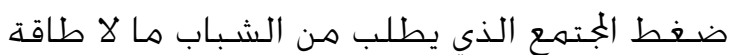

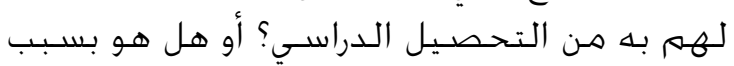

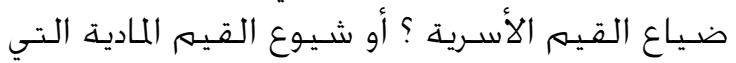

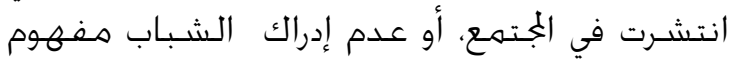

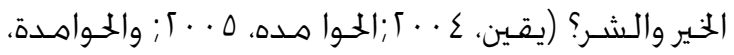

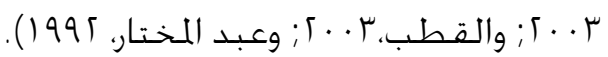
وقد نشـرت صـحيفة الشـرق الأوسـط (0. . ؟) تقريرا

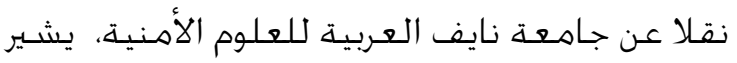
إلى أن نسبة العنف المدرسي بئن ناين طلاب وطالبات

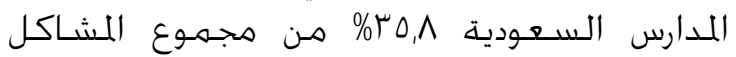

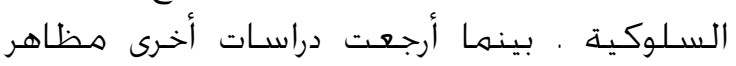

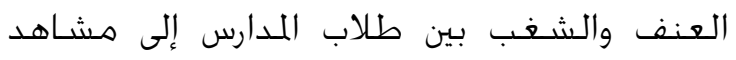

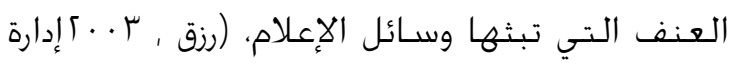

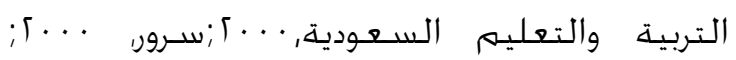

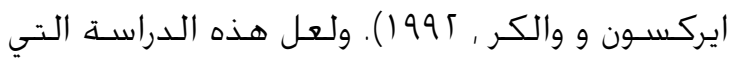

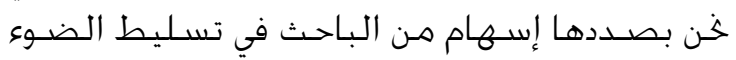

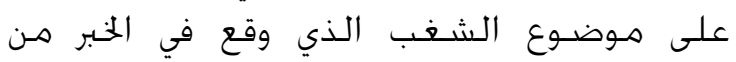

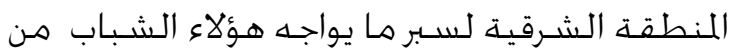

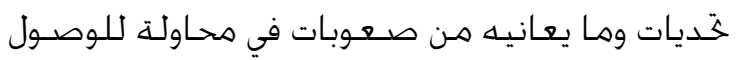

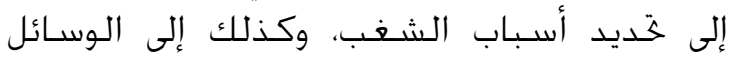

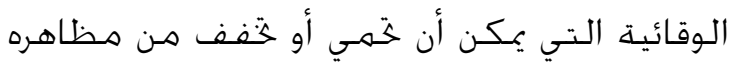

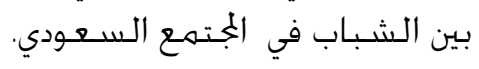

\section{مشكلة الدراسـة وأهميتها}

شهدت المنطقة الشـرقية العديد من محاولات الشـنب خلال المرحلة الماضـية التي كان مـن أهـهـها
ظاهـرة الشـخب من الظواهـر الاجتماعية والأمنية الجديرة بالدراسـة والفهـم والتنقيب، إذ أن دراستها النها

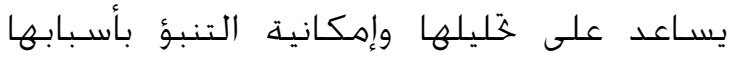

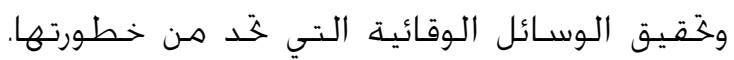

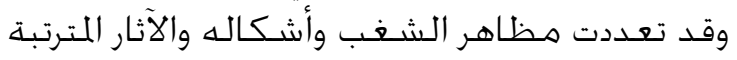

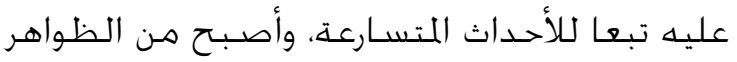

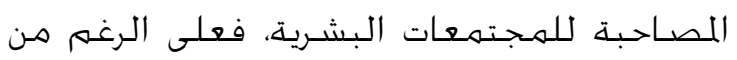

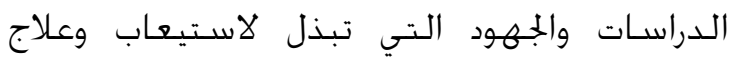

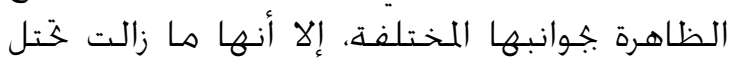

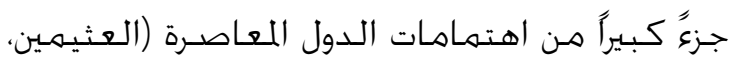

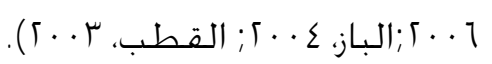

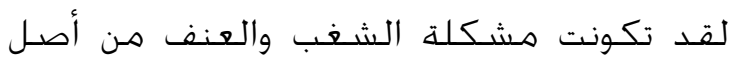

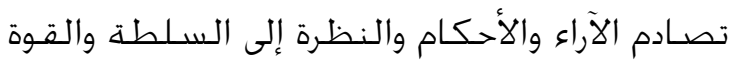

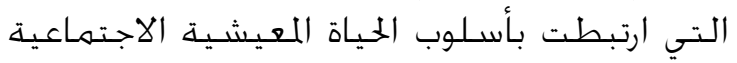

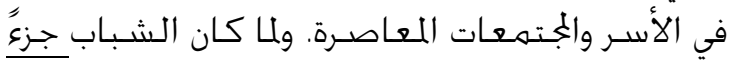

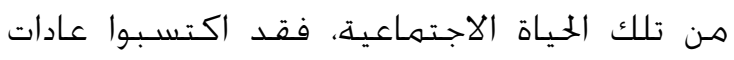

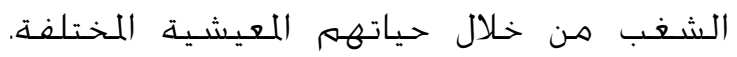

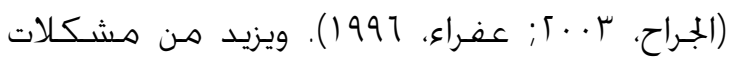

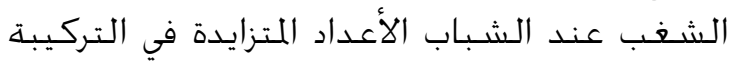

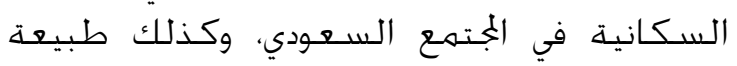

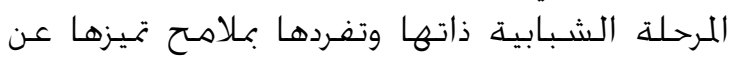

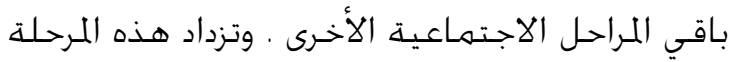

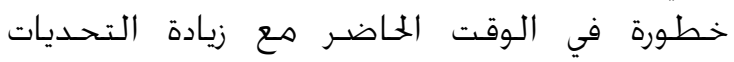

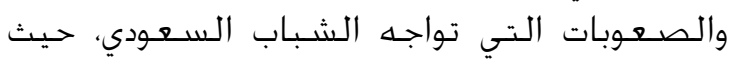

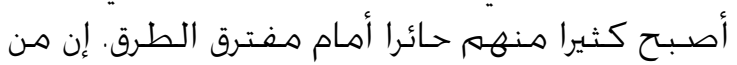

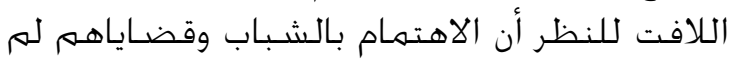

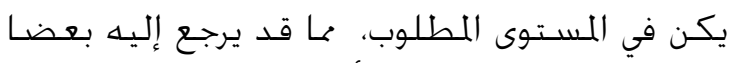

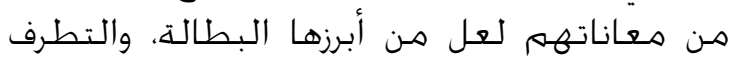

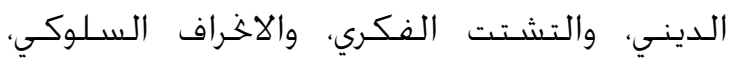

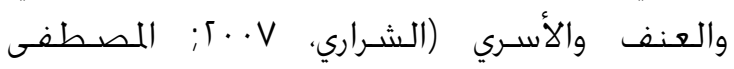

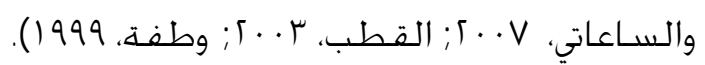

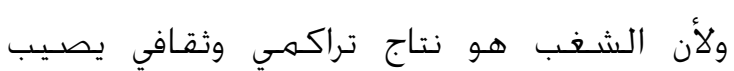

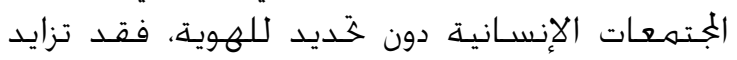
بوتيرة تصاعدية شغلت اهتمام الباحثين واللفكرين

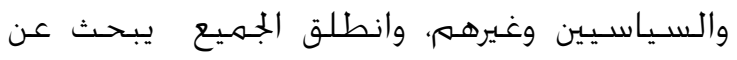

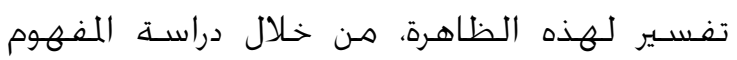
النفسي أو البيئي أو الاجتماعي أو القانوني، الذي داهي

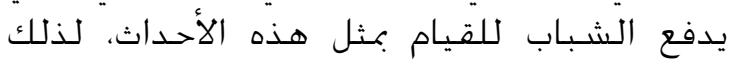

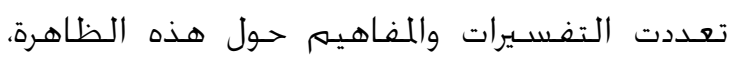

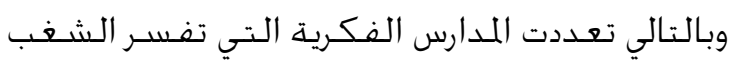


الظاهرة واللين المبطن عن طريق تطبيق الأنظمة والتعليمات دون الخوض في لب وجوهر المشكلة. وحول ما يمدث من شغب في المملكة العربية

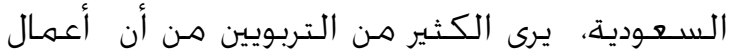

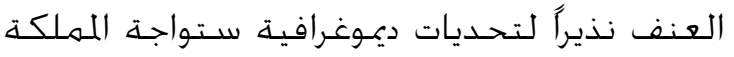

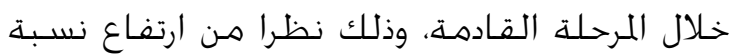

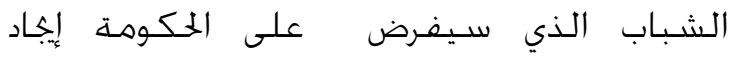

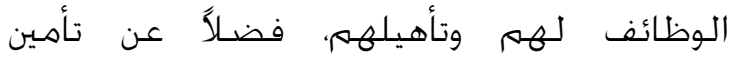

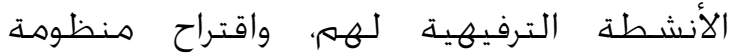

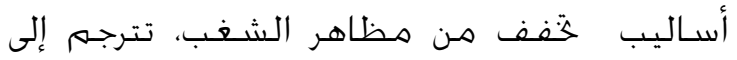

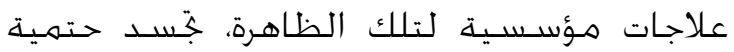

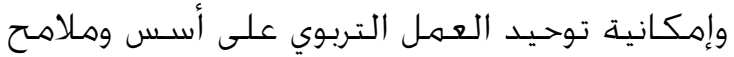
واضحـة (الجريدة، 9 + · ؟). ويمكن أن نلخـص مشكلة الدراسـة الحالية في أنها

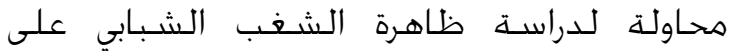

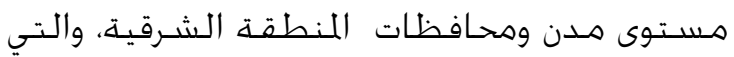

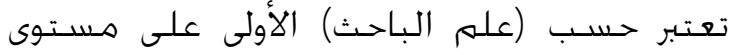

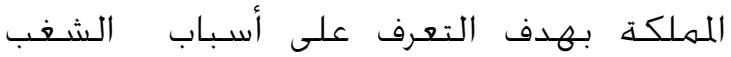

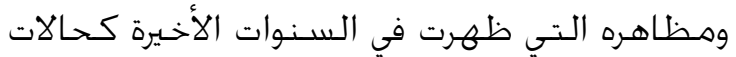

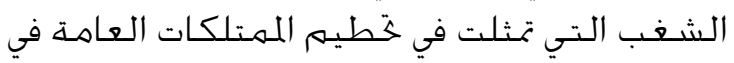

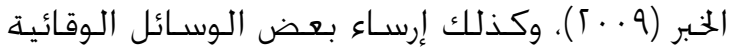

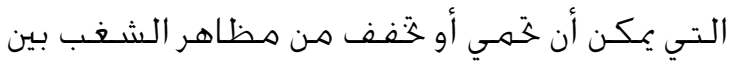

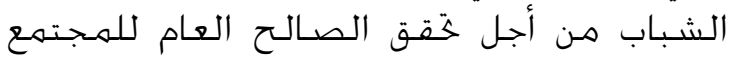
السعودي.

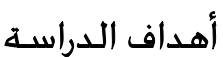
تسـعى الدراسـة الحالية إلى التعرف على: ا. واقع ظاهرة الشَب بين الشـباب في المنطقة الشـرقية من وجهة نظر العينة.

ז. الفـروق في أسباب الشـغب بين الشباب تبعا للمـدينة، وفئات مجتهـع الدراســة.

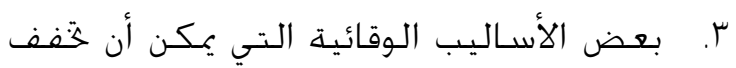

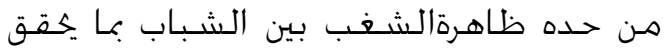

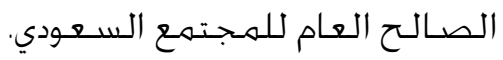

\section{تسـاؤلات الدراسـة}

ا. ما أسباب الشغب بين الشباب من وجهة نظر عينة الدراســـ الباب

ז. هل توجـد فروقا ذات دلالة إحصـائية في أسباب السباب

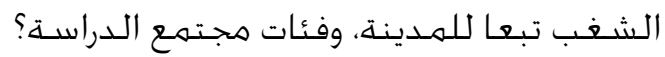

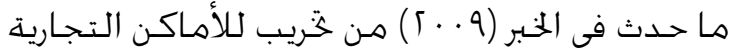

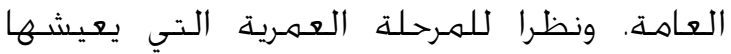

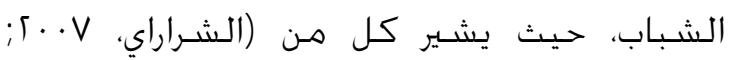

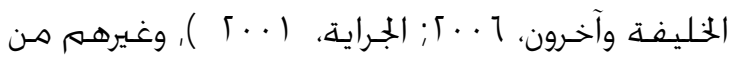

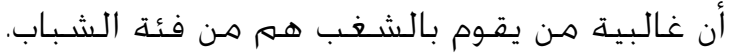

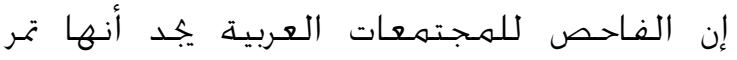

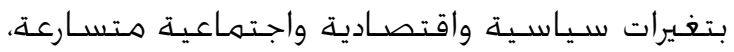

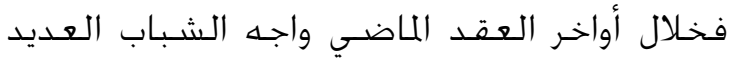

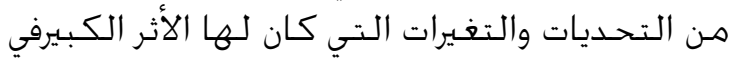

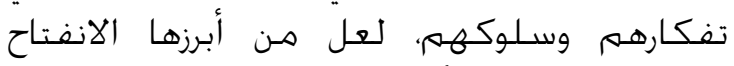

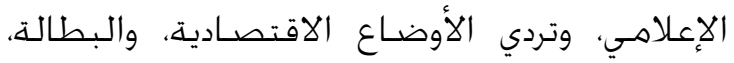

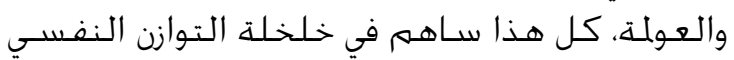

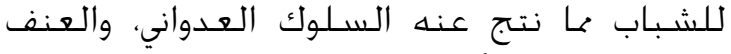

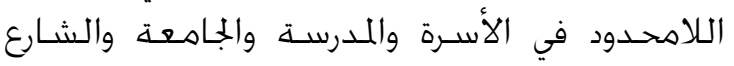

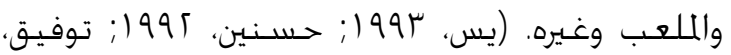

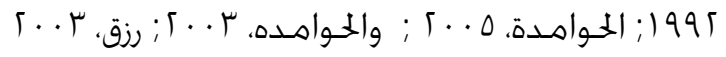

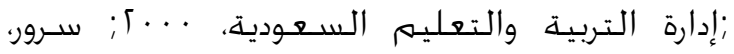

(Candace et al., 1992; Solomon, 2000 ؛....

بالإضـافة إلى كل ما سبق، فإن مـرحلة الشـباب وما

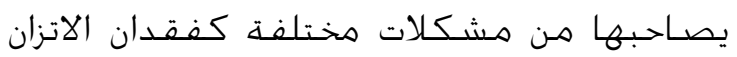

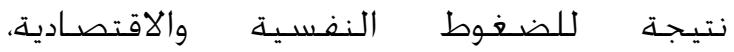

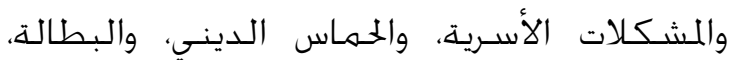

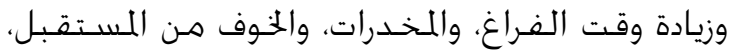

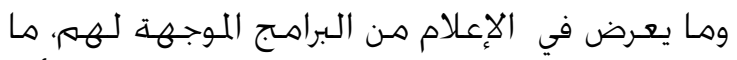

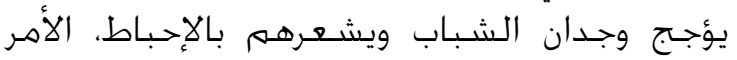

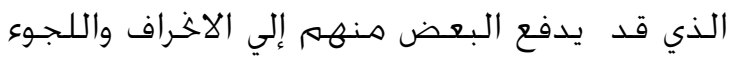

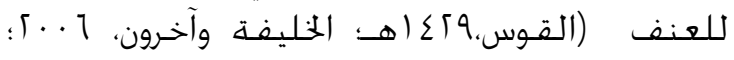
ال Joram, 1993

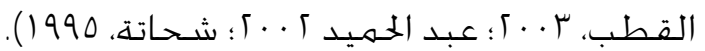

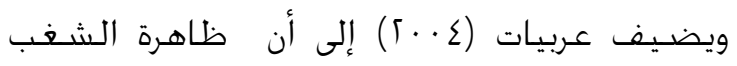

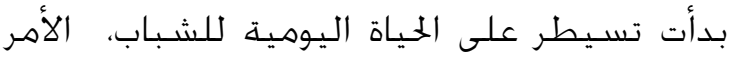
الذي دفع بعضهمه إلى خسـس خطرها واعتبارها

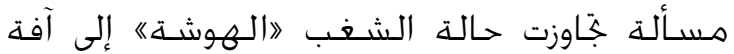

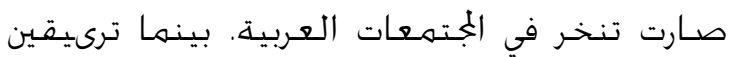

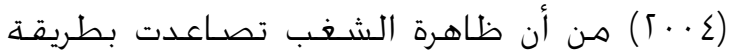
أثارت القـلق واستـدعت اهت اهتمام المربين والقائمـين.

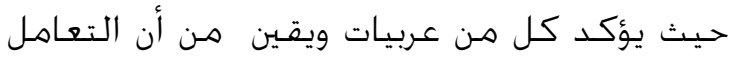

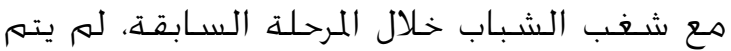

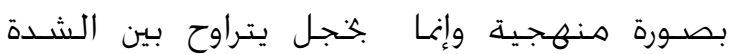




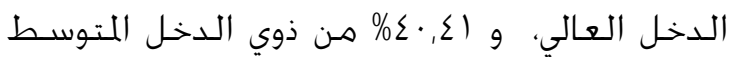

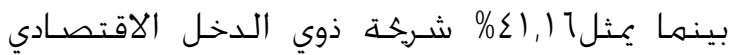

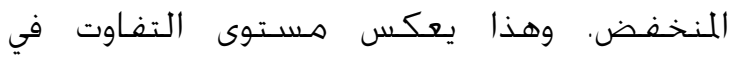

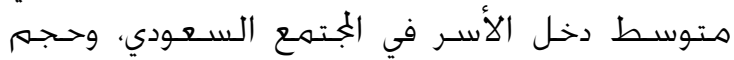

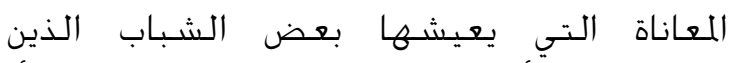

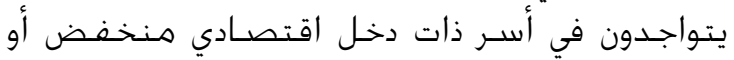

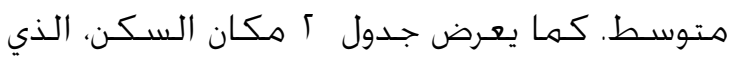

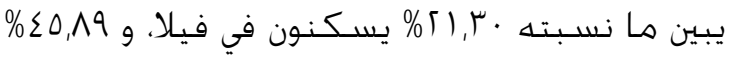

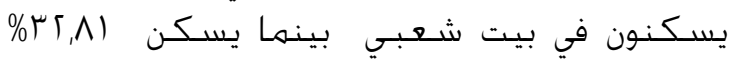

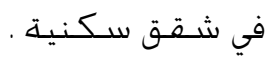

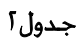

عينة الدراسه حسب الحالة الاقتصادية، ومكان الإقامة

\begin{tabular}{|c|c|c|c|c|c|}
\hline النسئبة & العدد & الاقامة مكان & المئسبة & العدد & الاقتصادية \\
\hline Г1.\%. & $V \wedge \Lambda$ & فيلا & $\mid V . \wedge \varepsilon$ & 77. & عسال مستوى \\
\hline$\sum 0.19$ & $179 \wedge$ & شعبـي & $\varepsilon \cdot \Sigma l$ & $1 \leqslant 90$ & متوستوى \\
\hline 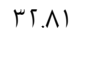 & $151 \varepsilon$ & شقـه & $\sum 1 . \mathrm{V} T$ & $10 \Sigma 0$ & منـخــض \\
\hline \% . . & rV.. & الجمهوع & $\%$ & $r v$. & الجمهموع \\
\hline
\end{tabular}

أداة الدراسـة

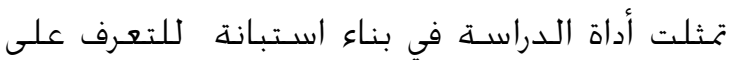

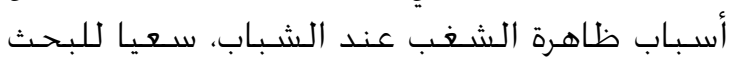

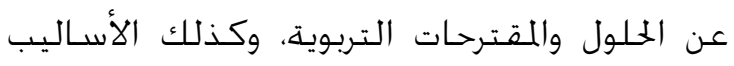

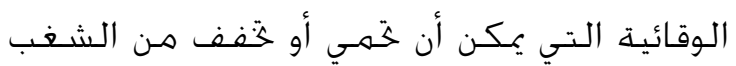

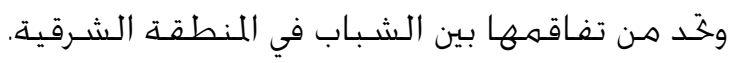

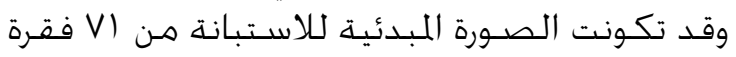

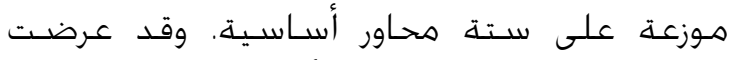

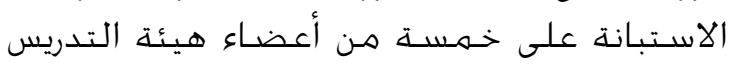

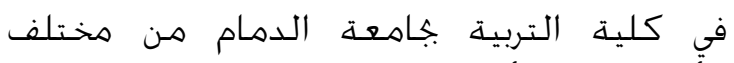

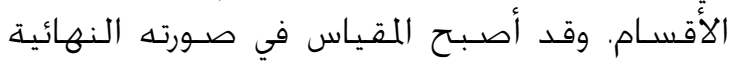

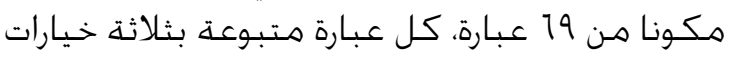

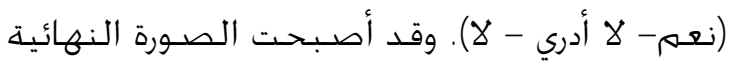

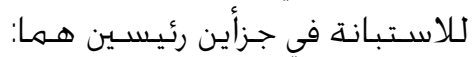

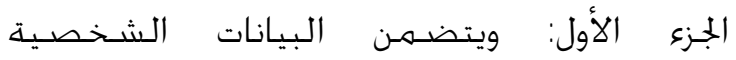

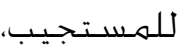

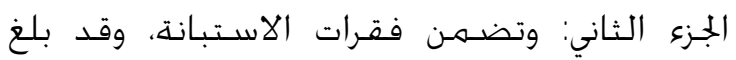

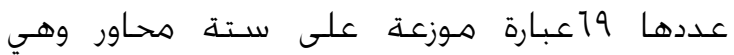

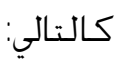

". ما الأسـاليب الوقائية التي يمكن أن تسـاهم في

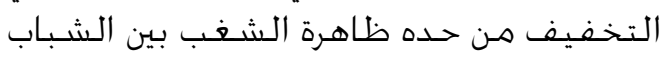

$$
\text { في المنطقـة الشـرقية؟ من فئه }
$$

\section{الطريقة والإجراءات}

المنهج

استخـدم الباحث المنهج الوصفي وذلك الملاءمته

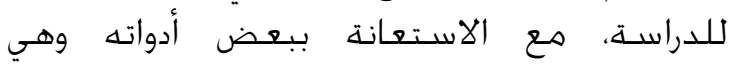

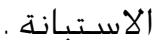

عينة الدراسـة

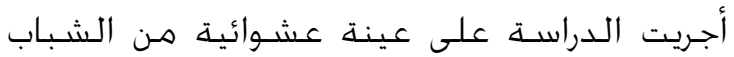

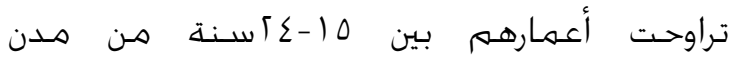

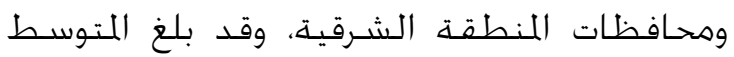

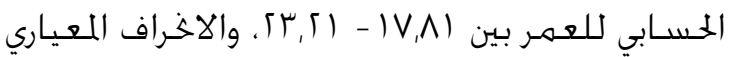

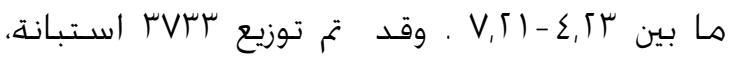

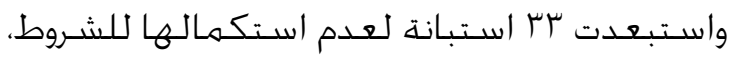

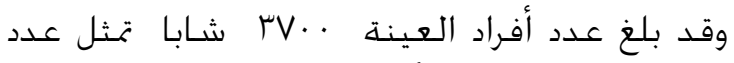

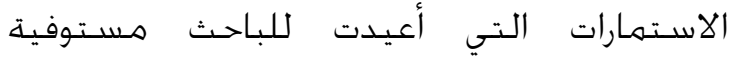

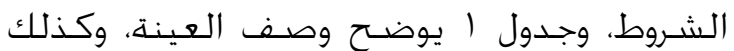

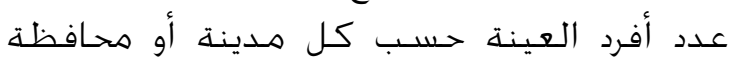

$$
\text { والنســبـ المئوية. }
$$

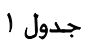

عينة الدراسـة حسب المدينة والمافظة وفئات العينة والنسب المئوية

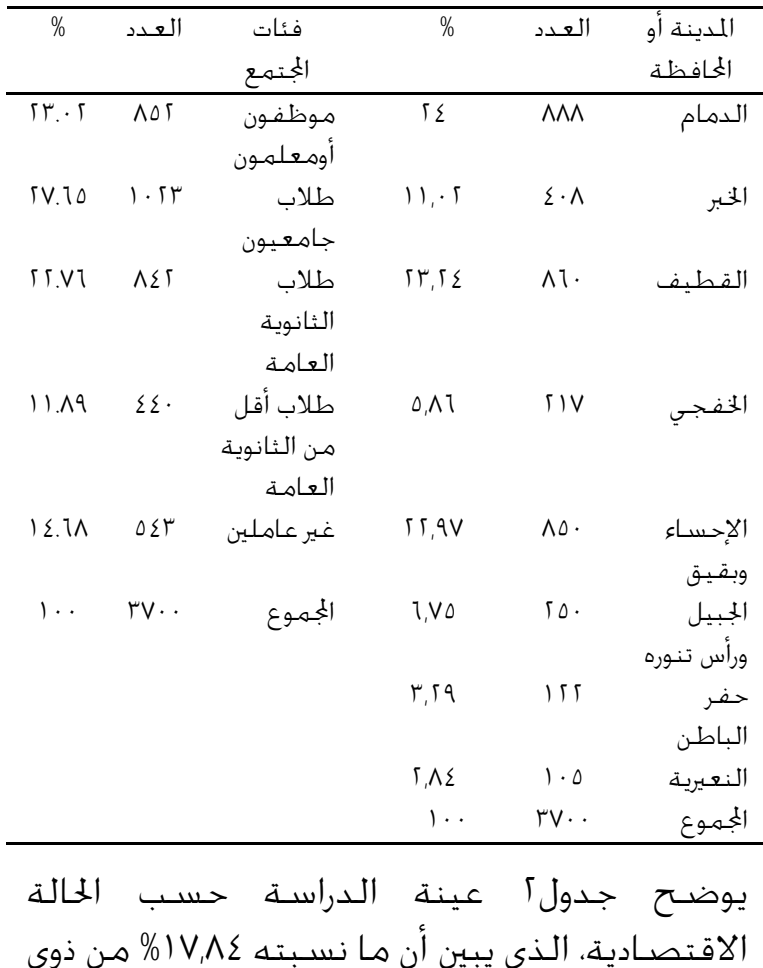

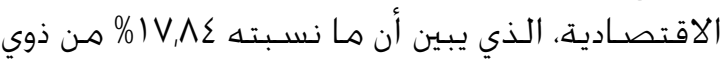


المعيارية، وختليل التباين الثنـائي، متبوعـا باللقـارنـات البعهديـة.

\section{نتائج الدراسـة}

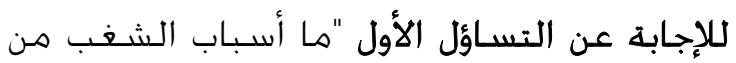

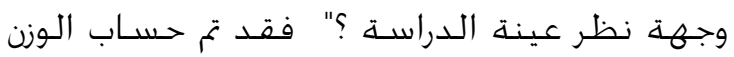

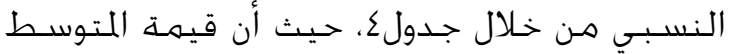

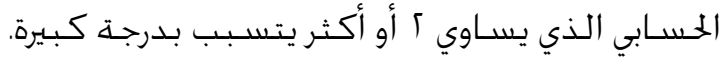

\section{جدول r}

معامل الاتساق الداخلي (كرونباخ ألفا) لكل من محاور الاستبانة

\begin{tabular}{|c|c|c|c|}
\hline معامل ألفـا & الفقــرات & محاور الـدراســــ & e \\
\hline$\cdot, 911$ & 9 & العـامل الاقتصـادى & 1 \\
\hline$\cdot, \wedge) 1$ & 0 & العـامـل الــينـي & r \\
\hline$\cdot, 9 \mu \mu$ & 11 & العـامل الي & r \\
\hline & & الصـحي /الترويحي & \\
\hline$\cdot . \Lambda 1 \%$ & 15 & العـاهـل الاجـــماعي & $\varepsilon$ \\
\hline$\cdot, \Lambda \wedge$ & 15 & العـامل الأسـري " " & 0 \\
\hline \multirow[t]{2}{*}{$\cdot, \wedge q$} & $\Gamma$. & الأسـاليب الوقائية & 1 \\
\hline & & المقتـرحـة & \\
\hline$\cdot, \wedge \mathrm{V}^{\mu}$ & 19 & المقياس ككل & \\
\hline
\end{tabular}

\section{جدول}

محاور الاستبانة مرتبة تنازليا حسب الوزن النسبي لدى عينة الدراسـة العـا

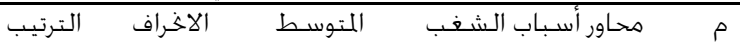

\begin{tabular}{|c|c|c|c|c|}
\hline & المعياري & الحسـابي & & \\
\hline 1 & $\cdot, \mu \Lambda$ & $\Gamma, 11$ & العامل الاقتصـادي & 1 \\
\hline r & $\cdot, \wedge \varepsilon$ & $\Gamma, 49$ & العـامل الديني & 广 \\
\hline r & $\cdot, \Delta \Lambda$ & $\Gamma, r V$ & العامل & $r$ \\
\hline$\Sigma$ & $\cdot, \wedge \vee$ & $\Gamma, \Gamma 0$ & 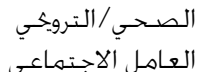 & $\varepsilon$ \\
\hline 0 & $\cdot, \wedge 1$ & $\Gamma, \cdot 1$ & العـامل الأسـري " & 0 \\
\hline
\end{tabular}

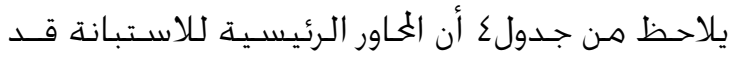

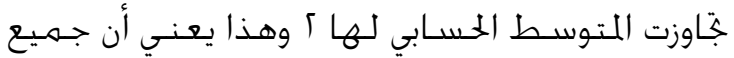

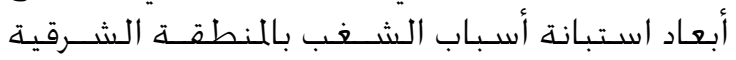

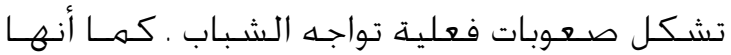

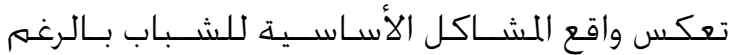

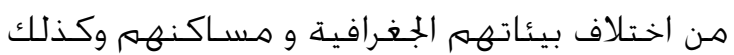

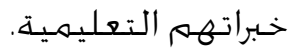

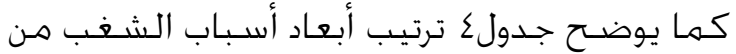

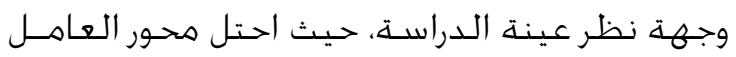

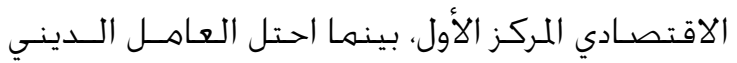

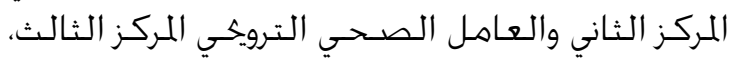

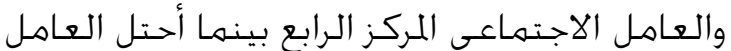

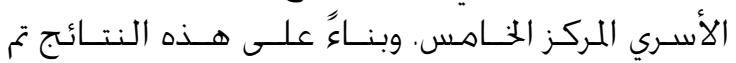

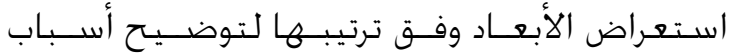

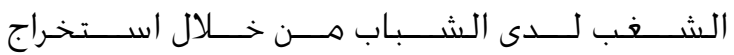

الغُور الأول: العامـل الاقتصـادي: وهو يمثل العبارات

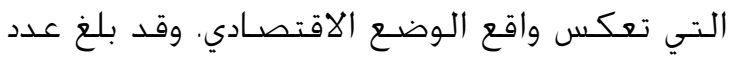
فقرات هذا المُور 9 عبارات.

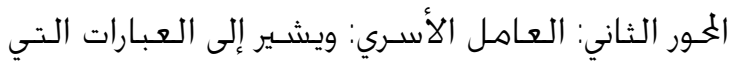

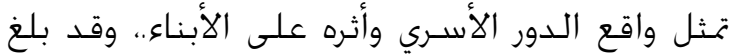
عدد فقـرات هذا المحور ه عبارات.

المحور الثالث: العامل الديني: ويشير إلى العبارات

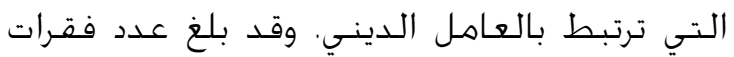
هذا المهور (اعبارة.

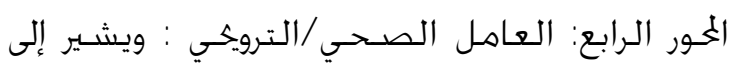

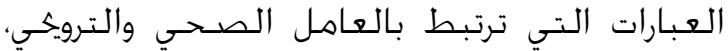
وقد بلغ عدد فقـرات هذا الغٔور ؟ ال عبارة. المُور الخامس: العامل الاجتماعي: ويشير إلى العبارات

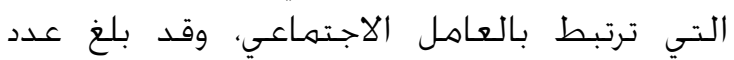
فقرات هذا المهور ؟ ال عبارة. المحور السـادس: الأسـاليب الوقائية اللقترحـة للتصـدي

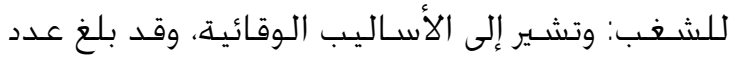
فقرات هذا المهور · آعبارة. الصـدق: اعتمد الباحث على الصـدق الظاهري Face Validity

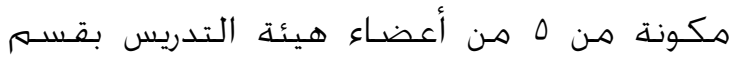

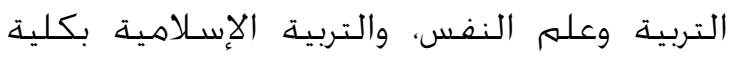

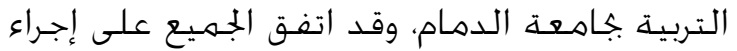

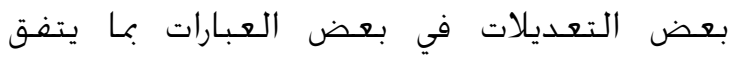

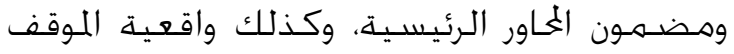

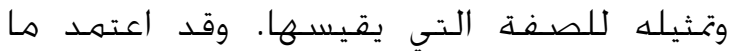

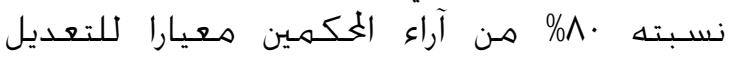
والإضـافة والحذف، واشتملت الاستبانة على 19

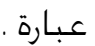
الثبــات: تم حســـاب معــاملات الثبــات باســتخـدام

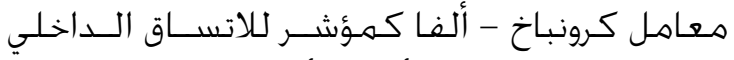

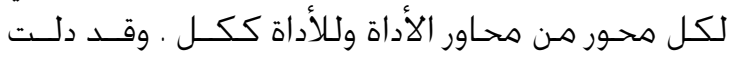

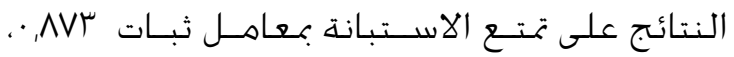

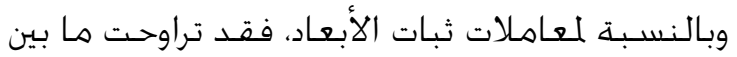

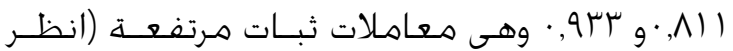

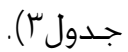
الأسـاليب الإحصـائية: تم استخــام برناهـج الإحصـاء

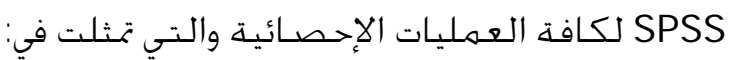

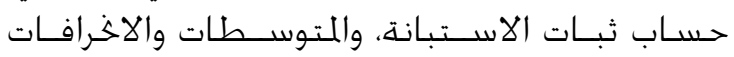




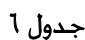

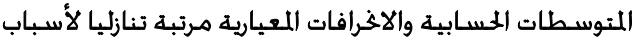

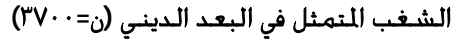

\begin{tabular}{|c|c|c|c|c|}
\hline الترتيب & الاخخراف المعياري & المستوسـي & العبارات & p \\
\hline 1 &., 91 & $\Gamma, \Delta \mu$ & الشتشابـة بعض المتطرفة دينيا & 1 \\
\hline r & $\cdot, \wedge 0$ & $\Gamma, 0$. & الاجتهاهـاعي في الشباب إلى العنف & 广 \\
\hline$r$ & $\cdot, 90$ & $\Gamma, \Sigma 9$ & إلى رفض الآخريني الذي يدعو & $r$ \\
\hline$\varepsilon$ & $\cdot, \mathrm{VT}$ & $\Gamma, \Sigma \mu$ & جعضود بعض رجال الدين في & $\varepsilon$ \\
\hline 0 & $\cdot, \wedge 0$ & 「,乏厂 & الشــــاب لإثارة العنف طلبة العلم & 0 \\
\hline 1 & $\cdot, 79$ & $\lceil, \Sigma)$ & 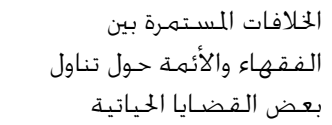 & 1 \\
\hline V & $\cdot, \sum \mu$ & $\Gamma, \Sigma$. & مصالح شـخصلال الدين لخدمة & V \\
\hline$\wedge$ & $\cdot, 95$ & ז, ז & ضــف الـوازع الدينـي لدى & $\wedge$ \\
\hline 9 & 1,10 & $\Gamma, \Gamma \varepsilon$ & 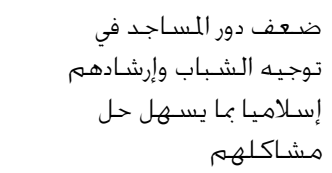 & 9 \\
\hline 1. & $\cdot, \sum \mu$ & $\Gamma, \Gamma \mu$ & 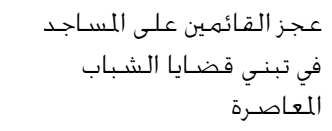 & . \\
\hline 11 & 5,19 & & ضعف برامهج التثقيف الديني & $\begin{array}{l}1 \\
1\end{array}$ \\
\hline
\end{tabular}

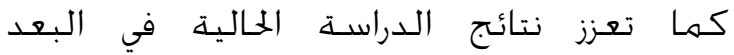

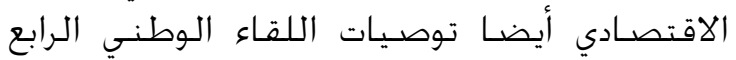
للحوار الفكري الذي عقد في المنطقة الشـرقية

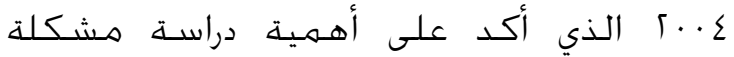

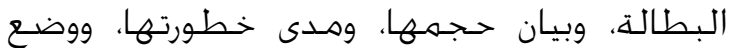
البرامج الكفيلة بمعالجتها، وإنشاء هيئة عليا للموارد البشرية وتنظيم عملية التوظيف في القطاعين العام والخاص، وتنسق جهود كافة الجهات

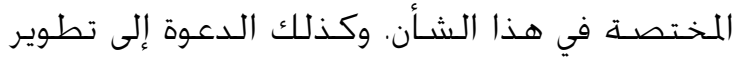

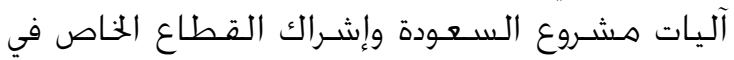

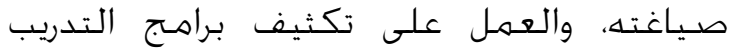

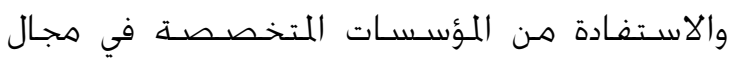
التدريب وتطوير المهارات لتوفير الكفاية المؤهلة.

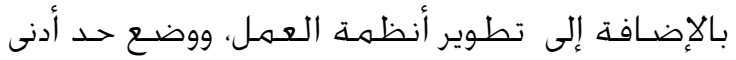

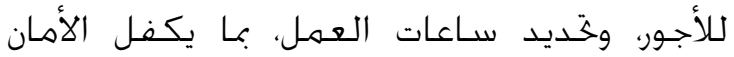

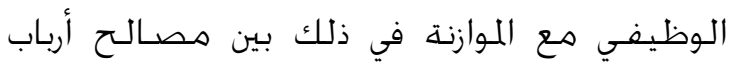
العمل وحقـوق العاملين.

المتوسـطات الحســابية والاخرافـات العـياريــة لجميـع

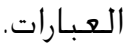

يبين جدوله ترتيبا تنازليا للمتوسطات الحسابية

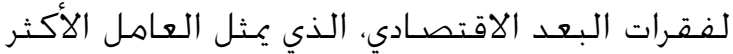

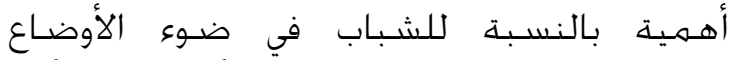

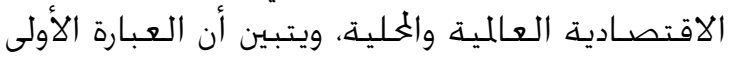

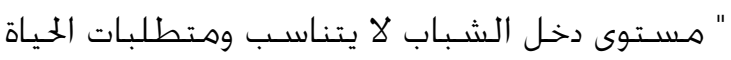

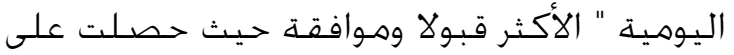

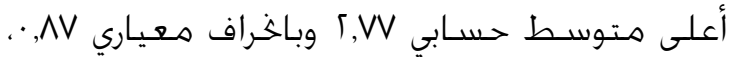
أما أدنى متوسـط منس حسابي فكان للعبارة الأخيرة

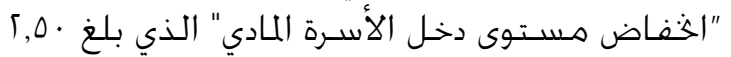

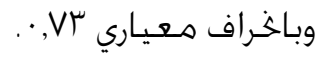

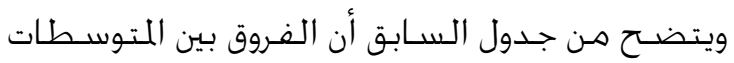

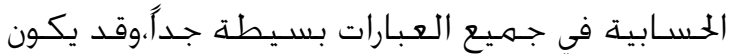

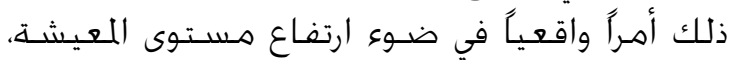

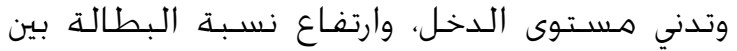

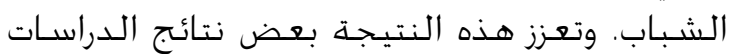
السـابقة مثل دراسـة (المصطفى والسـاعاتي

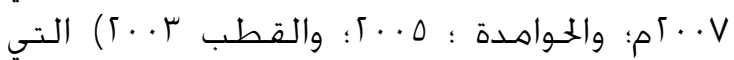

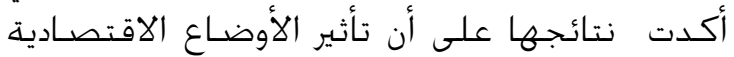

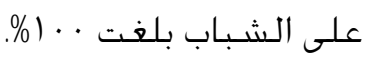

جدول 0

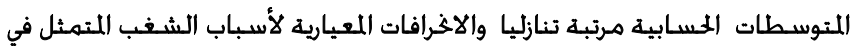
البعد الاقتصادي (نV. (rV)

\begin{tabular}{|c|c|c|c|c|}
\hline 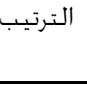 & اللعخراف & المتوسـطي & العبارات & p \\
\hline 1 & $\cdot, \wedge \mathrm{V}$ & $\ulcorner, \mathrm{VV}$ & 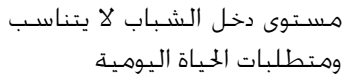 & 1 \\
\hline 「 & $\cdot, \wedge)$ & $\Gamma, 79$ & 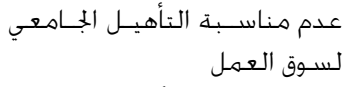 & r \\
\hline$r$ & $\cdot, \Lambda \mu$ & 「, IV & 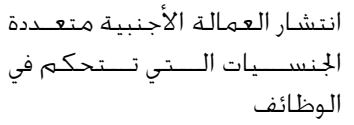 & $r$ \\
\hline$\varepsilon$ & $\cdot, 10$ & $\Gamma, 10$ & 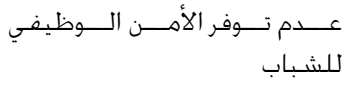 & $\varepsilon$ \\
\hline 0 & $\cdot, \leq 0$ & $\lceil, \Delta \wedge$ & 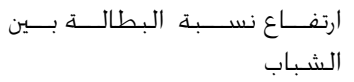 & 0 \\
\hline 1 & $\cdot, \Lambda r$ & $\Gamma, \Delta \Delta$ & 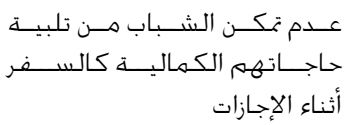 & 1 \\
\hline V & $\cdot, 19$ & $\Gamma, 0 \Sigma$ & ارتفـاع مسـتوى المعيشـة & V \\
\hline$\wedge$ & $\cdot, \mathrm{V} \Gamma$ & $\Gamma, \Delta r$ & 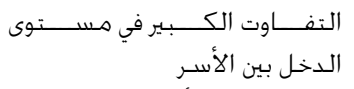 & $\wedge$ \\
\hline 9 & $\cdot, \mathrm{V}{ }^{\mu}$ & $\Gamma, 0$. & اخففاض دخل الأسـرة المادي & 9 \\
\hline
\end{tabular}


تبني قضايا الشباب وتوجيهـهم إسـلاميا بما يسهـل معهل

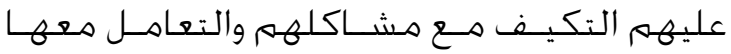

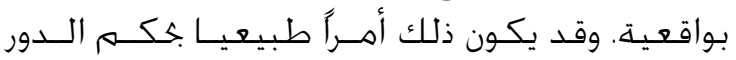

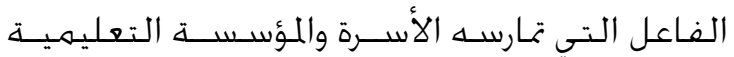

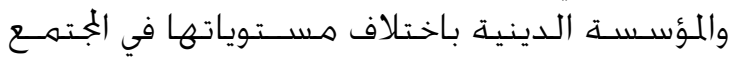

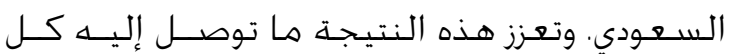

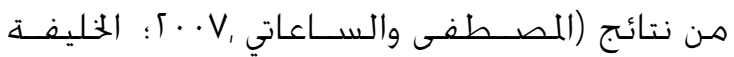

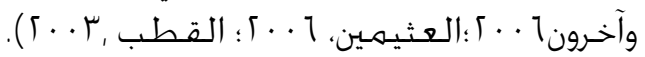

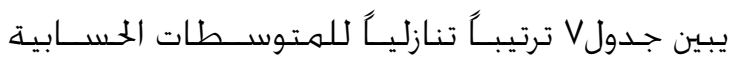

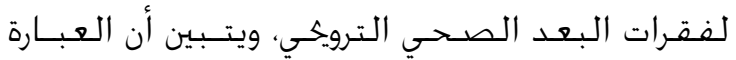

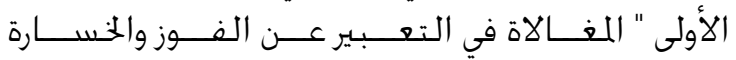

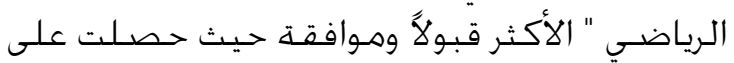

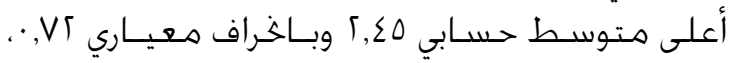

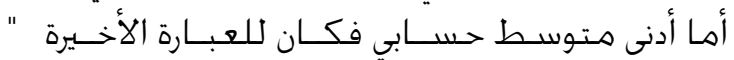

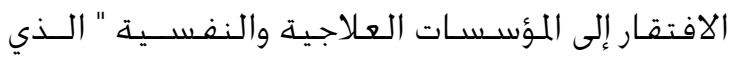

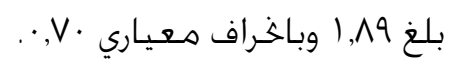

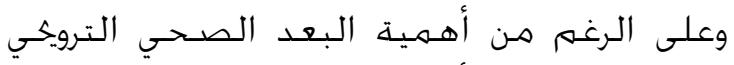

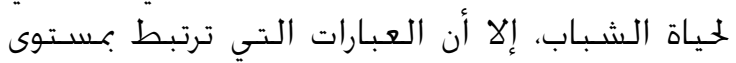

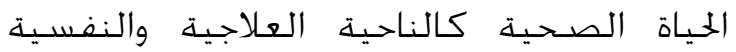

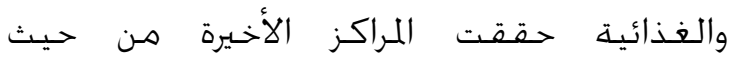

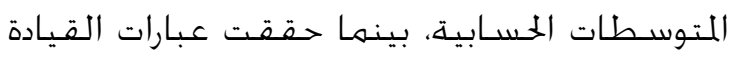

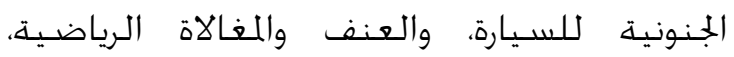

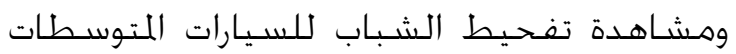

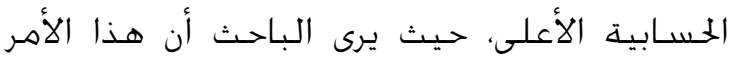

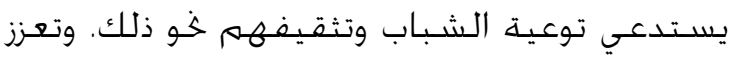

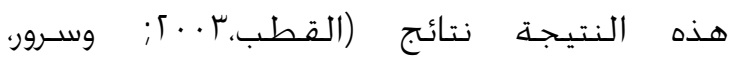

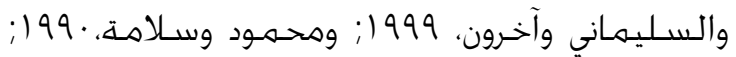

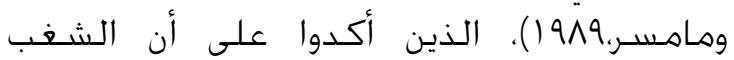

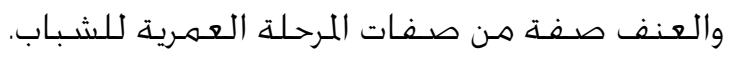

وتتفق نتائج الدراسـة الحالية مع نتائج دراسـة

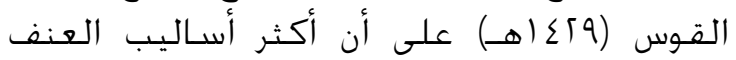

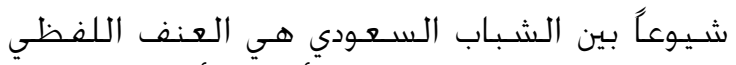

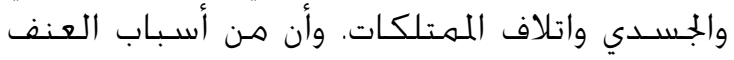

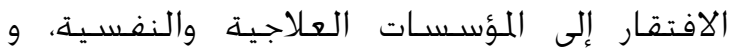

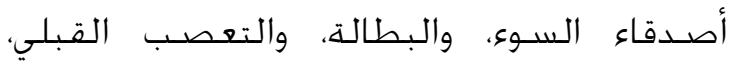
وقسـوة الآباء، التعصـب الرياضـي. يبين جدول ^ ترتيبًا تنازليًً للمتوسـطات الحسـابية

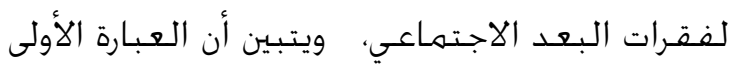

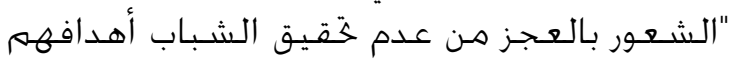

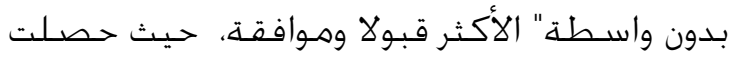

يبين جـدول1 ترتيبـا تنازليـا للمتوســـات الحســابية

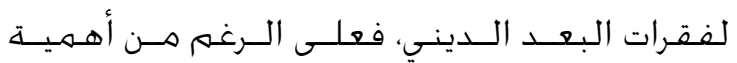

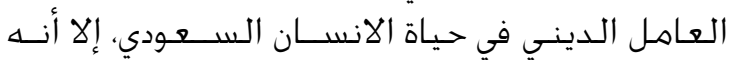

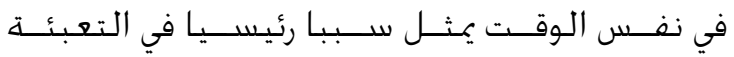

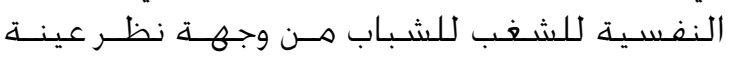

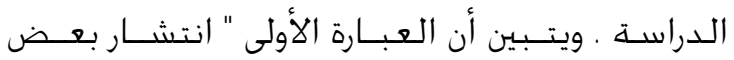

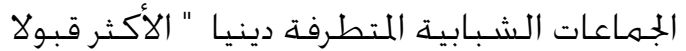

جدول

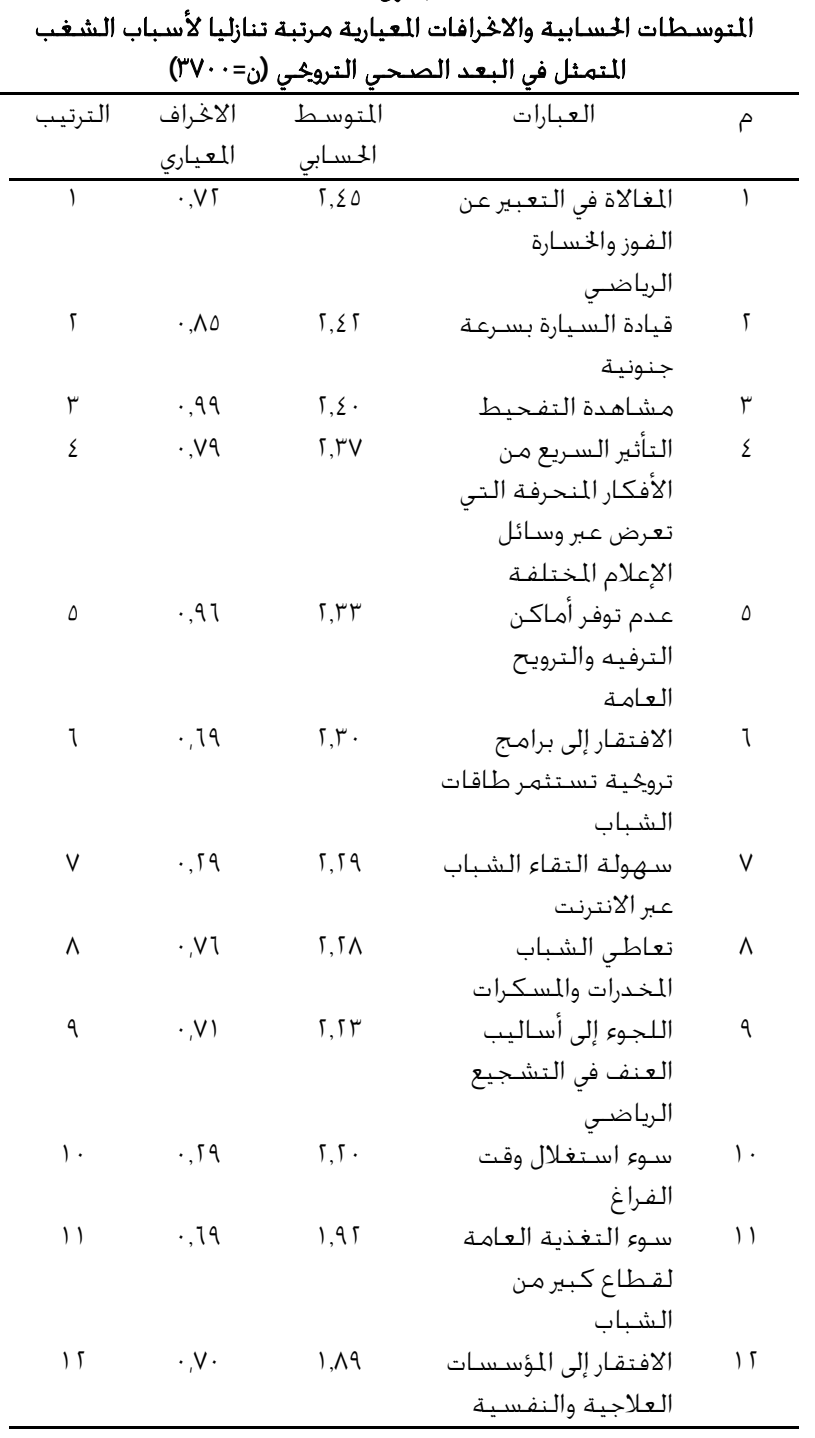

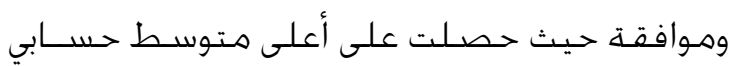

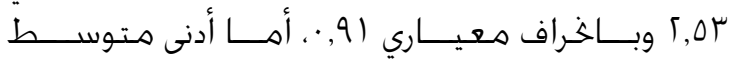

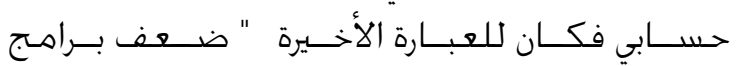

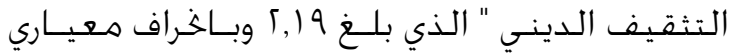
$\cdot, \Sigma$.

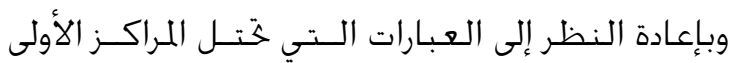

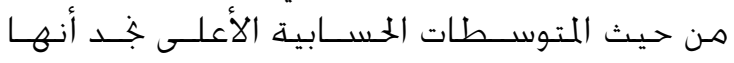

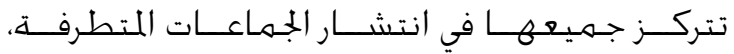

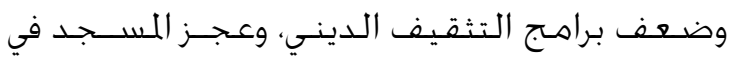


حسـب التخـصـص والخبرة. وتعـزز هـذه النتيـجـة نتـائج

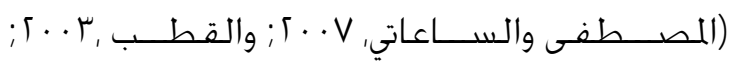
ومحسمود وسـلامة, · 99 ( ).

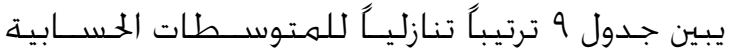

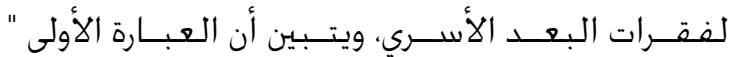

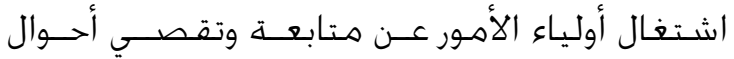

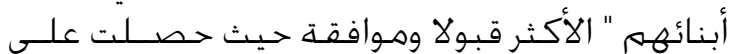

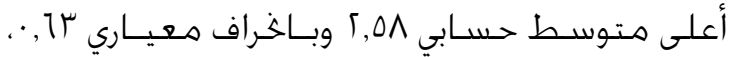

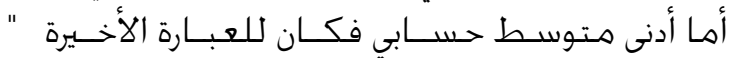

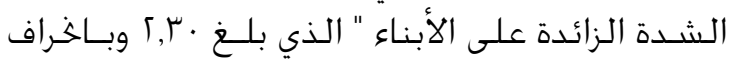

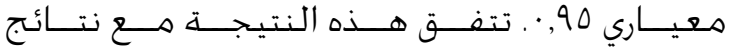

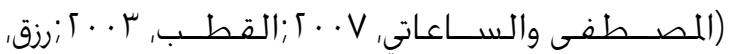

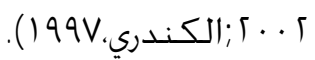

جدول 9

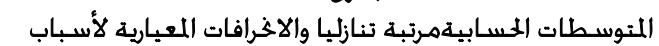

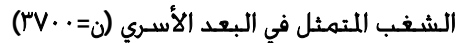

\begin{tabular}{|c|c|c|c|c|}
\hline الترتيب & الالعخراف & المتوسـطي & العبارات & p \\
\hline 1 & $\cdot, 7 \mu$ & $\Gamma, \Delta \Lambda$ & أحن متال أبنال أولياء الأمور & 1 \\
\hline i & $\cdot, \mathrm{V} \Gamma$ & $\Gamma, \Sigma \mathrm{V}$ & الصياب القدة في المجنمع & r \\
\hline$r$ & $\cdot, \mathrm{Va}$ & $\lceil, \Sigma)$ & 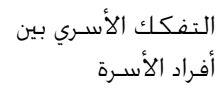 & $r$ \\
\hline$\varepsilon$ & $\cdot, \wedge$. & $\Gamma, \mu \uparrow$ & التدليل الزائد للأبناء & $\varepsilon$ \\
\hline 0 & $\cdot, 90$ & $\Gamma, \Gamma$. & الأشنـــة الزائدة على & 0 \\
\hline
\end{tabular}

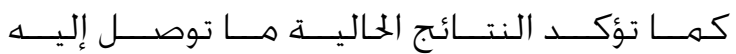

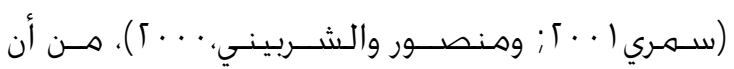

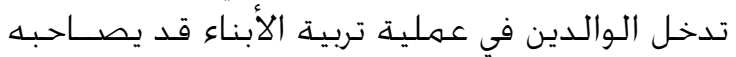

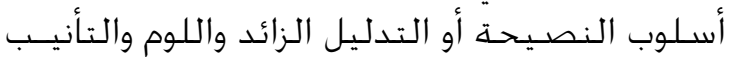

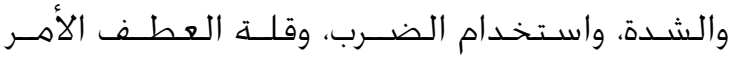

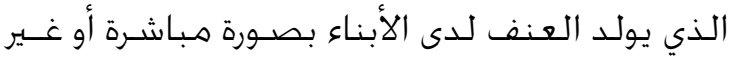

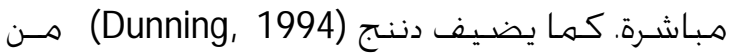

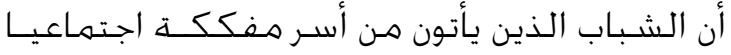

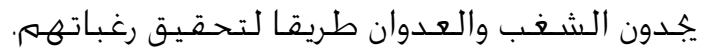

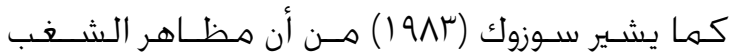

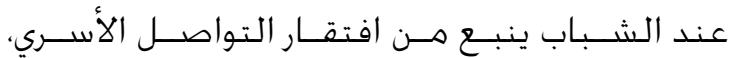

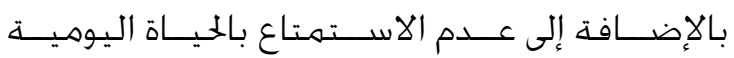

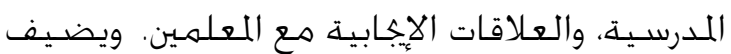

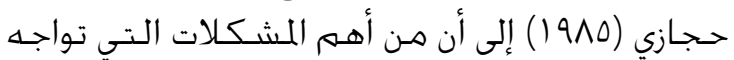

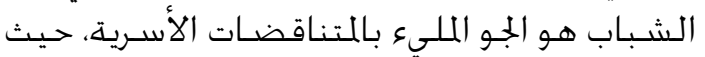

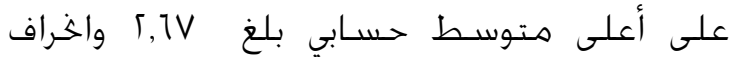

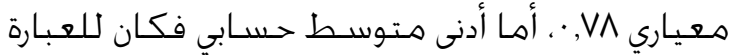

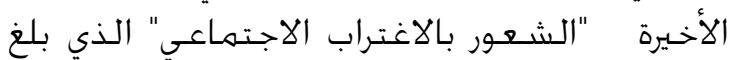

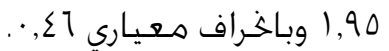

جدول

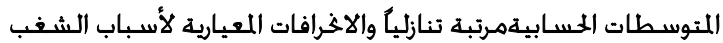

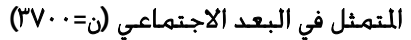

\begin{tabular}{|c|c|c|c|c|}
\hline الترتيب & الالعباري & المسوسـي المسبي & العبارات & p \\
\hline 1 & $\cdot, \vee \wedge$ & 「, IV & 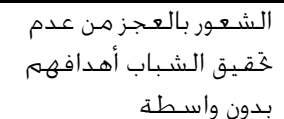 & 1 \\
\hline$\Gamma$ & $\cdot, 9$. & $\Gamma, \Sigma V$ & للجنـــ معآكســات الشباب & $\Gamma$ \\
\hline$r$ & $\cdot, 90$ & $\Gamma, \Sigma 0$ & في لبسـهـم وسـلوكهـهم الشـاب بالمشير & $r$ \\
\hline$\varepsilon$ & $\cdot, \wedge 9$ & $\lceil, \Sigma$. & العنف لدى الشبارة البرامج الإعلامية & $\varepsilon$ \\
\hline 0 & $\cdot, 71$ & $\Gamma, \Gamma \varepsilon$ & تصليد الحياة الغربية & 0 \\
\hline 1 & $\cdot, \wedge 9$ & $\Gamma, \Gamma^{\prime}$ & 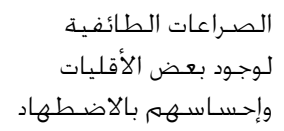 & 1 \\
\hline V & $\cdot, r 9$ & $5, \Gamma 9$ & 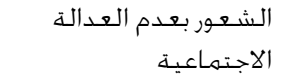 & V \\
\hline$\wedge$ & $\cdot, 0$. & $\lceil,\lceil\wedge$ & 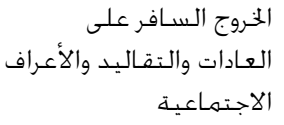 & $\wedge$ \\
\hline 9 & $\cdot, 95$ & $\lceil, \Gamma$. & 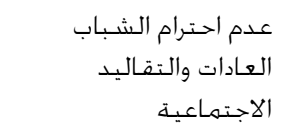 & 9 \\
\hline 1. & ·, OI & 5,10 & الهجرات المكثفة للشباب & 1. \\
\hline 11 & $\cdot, 09$ & 1,90 & $\begin{array}{r}\text { الشتعور بالاغتراب } \\
\text { الاجتماعي }\end{array}$ & 11 \\
\hline 11 & $\cdot, \Sigma 1$ & $1, \wedge 0$ & ساخل المجتمع التكيف الاجتماعي & 15 \\
\hline
\end{tabular}

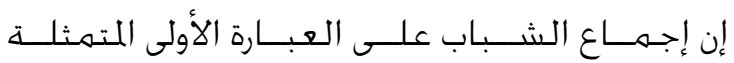

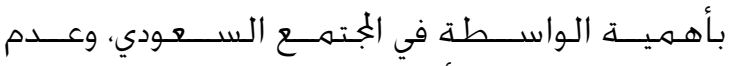

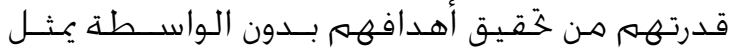

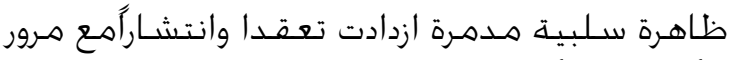

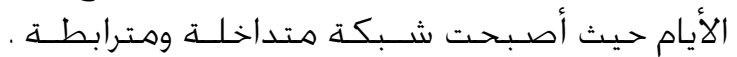

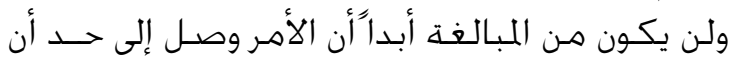

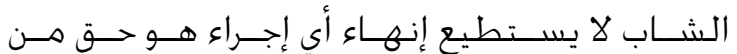

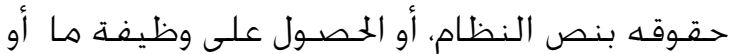

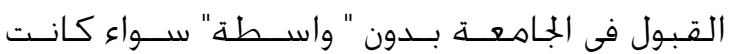

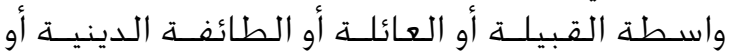

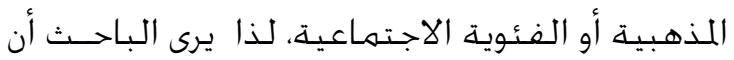

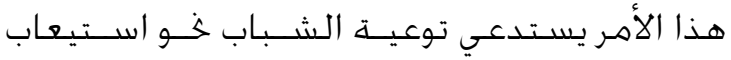

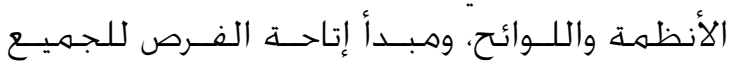


الدراسـة، فجـدول يشـير إلى أنه توجــ فروق بين

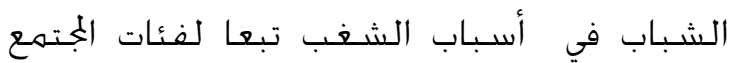

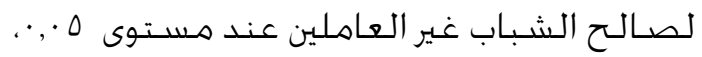

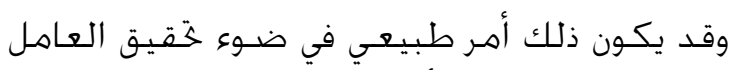
الاقتصـادي المركز الأول من وجهة فئه نظر الشباب. بالإضـافة إلى ذلك تمثل عينة الشباب غير الإير العاملين

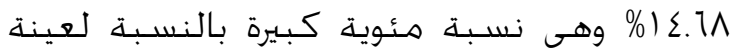

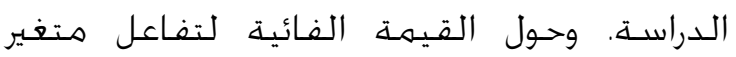

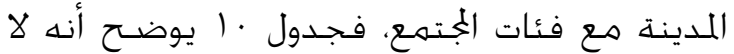
توجد فروقا تذكر بينهما.

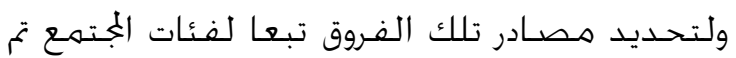

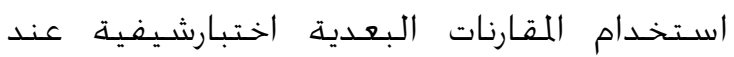

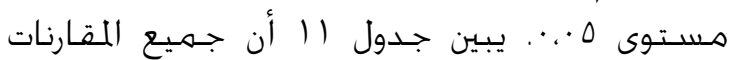

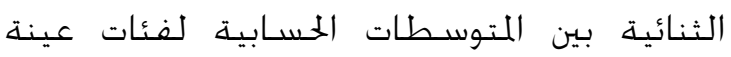

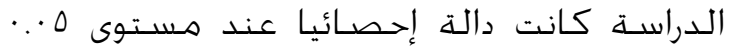

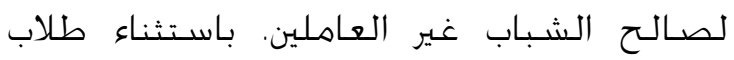

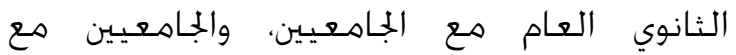

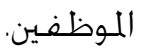
كما يوضـح الجـدول أيضـا أن غير العاملين احتلوا

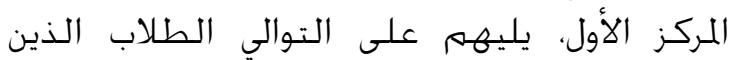

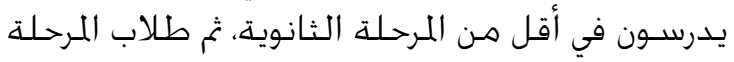

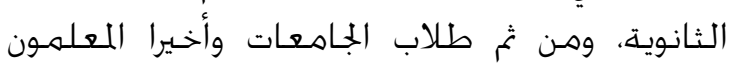
والموظفون.

وللإجابة على التسـاؤل الثالث، ما الوسـائل الوقائية التي يمكن أن تسهم في التخفيف من النهاول الناهرة

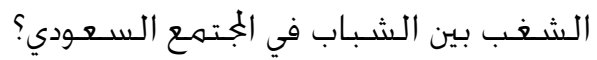

لم تعـد الأسـرة قادرة على تدريب الأبنــاء علــي خحمـل

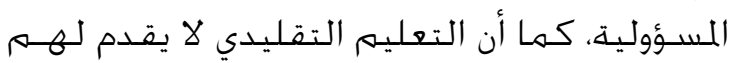

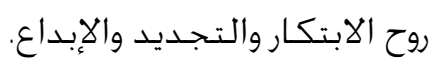$$
\text { جدول }
$$

\begin{tabular}{|c|c|c|c|c|c|}
\hline مستو & قيهة & متوسط & درجة & مجهوع & مص \\
\hline$s$ & ف & المربعات & الحري & المربعات & رد \\
\hline \multirow[t]{2}{*}{ الدلالة } & & & & & التبادِ \\
\hline & & & & & $\dot{u}$ \\
\hline \multirow{2}{*}{ دالة } & 1,15 & $\mathrm{~V} 10, \mathrm{~V} 1$ & v & $r \wedge \Lambda, \leq 0$ & المدين \\
\hline & & & & & ف فئنات \\
\hline \multirow[t]{2}{*}{ دالة } & $0, \mu \varepsilon$ & $\sum 01, \Lambda V$ & $\varepsilon$ & $|r \varepsilon \cdot|$, & المجتهـ \\
\hline & & & & & لوع \\
\hline \multirow[t]{3}{*}{ غالة } & $1, \Gamma \wedge$ & $1 . r \varepsilon, \Gamma$ & 14 & $\sum \vee \wedge r, \Gamma$. & فئنات \\
\hline & & & & & اليجتهـ \\
\hline & & $11, \pi$ & riv & ז & 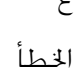 \\
\hline
\end{tabular}

واللإجابة عن التسـاؤل الثاني، لا توجد فروقاً ذات دلالة

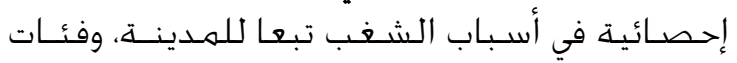

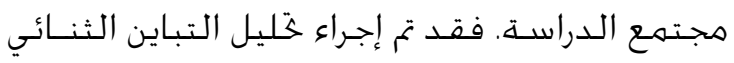

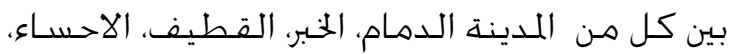

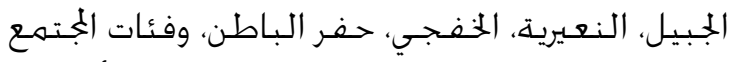

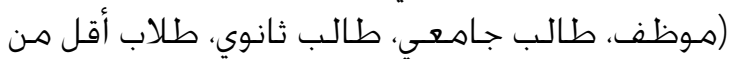

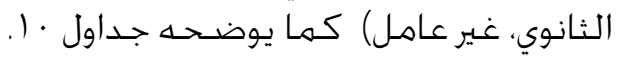

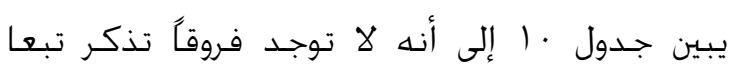

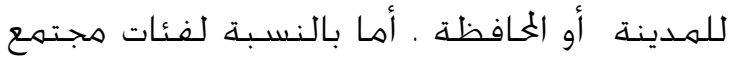

جدول 11

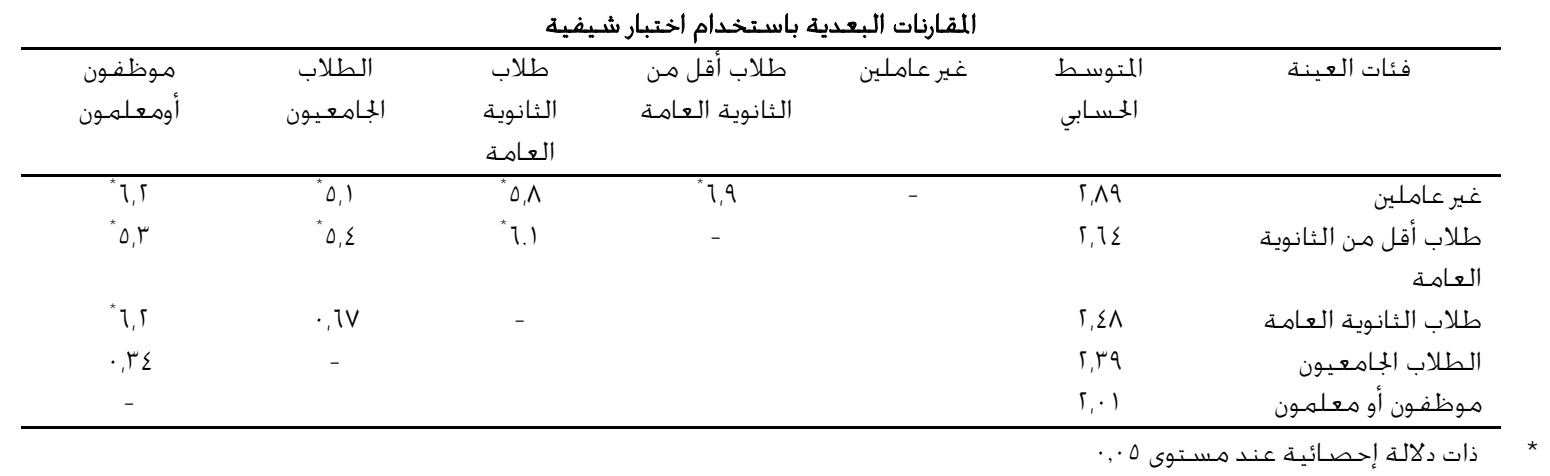


جدول 15

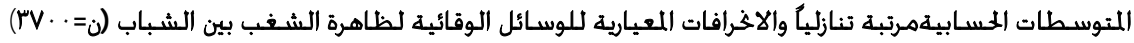

\begin{tabular}{|c|c|c|c|c|}
\hline الترتيب & 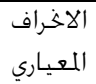 & المسابي & 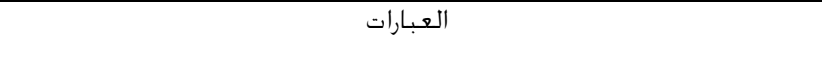 & p \\
\hline 1 & $\cdot, \Sigma 1$ & 「,V9 & توفير فرص عمـل للشـباب & 1 \\
\hline 广 & $\cdot, 1 \wedge$ & r,Vo & المواءمة بين ختصـصـات التعليم العالي وحـاجات سـوق العمل & r \\
\hline r & $\cdot, \mathrm{V} \Gamma$ & $\Gamma, \mathrm{V}$ & ضـمان فرص التعليم الجامعي للشباب ل & r \\
\hline$\varepsilon$ & $\cdot, \mathrm{VT}$ & $\Gamma, 09$ & محاربة المُسـوبية والماباة فيماً يتعلق بقضـايا الشـباب & $\varepsilon$ \\
\hline 0 & $\cdot, \mathrm{Vq}$ & $\Gamma, \Delta 0$ & 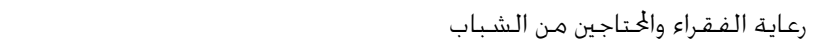 & 0 \\
\hline 1 & $\cdot, \mathrm{V} \Gamma$ & $\Gamma, 0$ & تَسين فرص استمرار الشـباب مواصلة تعليمهـم العالي & 1 \\
\hline V & $\cdot, 99$ & 「,乏० & تشـيع الأنشـطة الطلابية الداعمة لأسـاليب الحوار واحترام الآخرين & $\mathrm{v}$ \\
\hline$\wedge$ & $\cdot, 1)$ & 「,乏厂 & التثقيف الأسـري وتعزيز دورا لأســرة في تربية وتوجيه الأبناء & $\wedge$ \\
\hline 9 & $\cdot, \mathrm{Va}$ & $\Gamma, \Sigma$ & توفير نواد رياضية واجتماعية وثقافية جاذبة مجانية للشـباب تسـثـمر طاقاتهم & 9 \\
\hline 1. & $\cdot, 79$ & $\Gamma, \% 0$ & 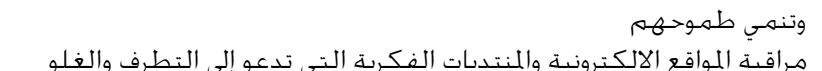 & 1. \\
\hline 11 & 1,11 & $\Gamma, r \mu$ & مكافحة المسكرات والمخدرات بأنواعها المختلفة & 11 \\
\hline 11 & $1, \cdot 1$ & t, ז t & توفير فرص حرية إبداء الرأي للشباب & 15 \\
\hline 14 & $\cdot, \wedge \Delta$ & t, ז $\mathrm{r}$ & إنشـاء مواقع متخصصصـة في الإنترنت للتصـدي للشـباب الذين يمارسـون الشغذب & 14 \\
\hline $1 \varepsilon$ & $\cdot, \mathrm{Va}$ & t, ז & وضع استراتيجية وطنية للإعلام لتفادي اخرافات الشباب & $1 \varepsilon$ \\
\hline 10 & $\cdot, \Sigma 9$ & 「, г & عمل برامج تلفزيونية توعوية لتعريف الشَباب بخطر الشَب & 10 \\
\hline 17 & $\cdot, \wedge 0$ & 5,19 & تيسـير سـبل الزواج للشباب لضـمان اسـتقرارهم النفسـي & 17 \\
\hline IV & $\cdot, \wedge 9$ & 「,1 & تفعيل جماعة الخي ودعمها وتشجبعها & IV \\
\hline 11 & $\cdot, 97$ & 1,90 & تبني الأئمة والخطباء خطابا توجيهيا للشباب & $1 \wedge$ \\
\hline 19 & $\cdot, \mathrm{Vq}$ & $1, \wedge 9$ & بث الَقِيم الإسـلامية في نفوس الشـباب مـن خـال برامج التعليم والإعلام & 19 \\
\hline 「. & $\cdot, \wedge 9$ & $1,5 \wedge$ & تدريب الشباب على ختمـل المسئولية والعمل التطوعي & r. \\
\hline
\end{tabular}

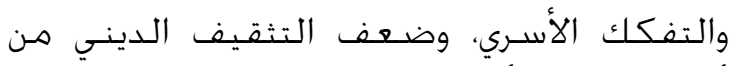

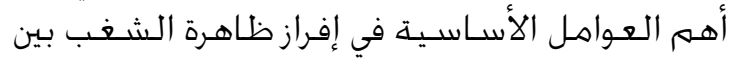
الشباب.وتعد فئة الشباب أكثر حسـاسـية وأكثر

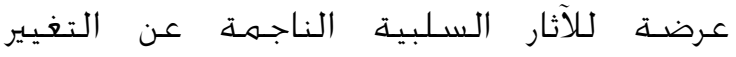

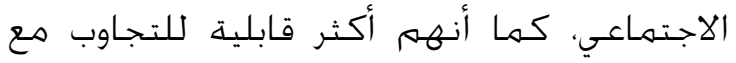

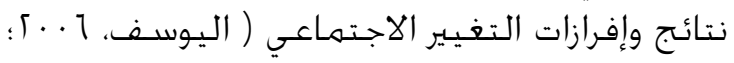

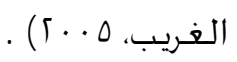

\section{الاستـنتاجات}

في ضـوء تسـاؤلات الــراسـة وأهـدافها، ومـا انتهـت إليـ هـن نتائج، يمكن اسـتـنتاج الآتي:

أوضسح نتائج التسـاؤل الأول ترتيب أبعاد

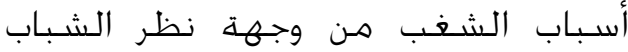
بالمنـطقة الشـرقية، كالتالي: حيـث أحتل محـور

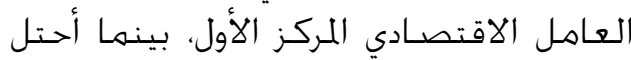

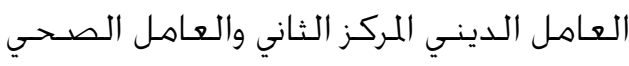

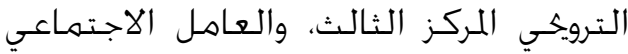

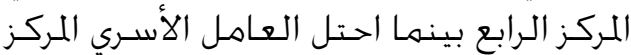
الأخسير.

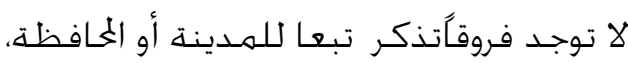

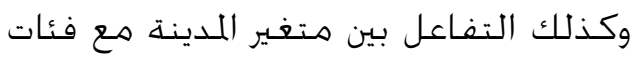

يبين جدول ؟ا ترتيبا تنازليا للمتوسـطات الخسـابية

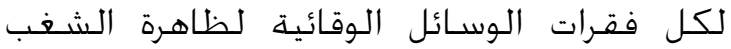

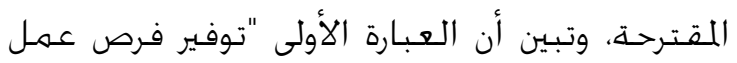

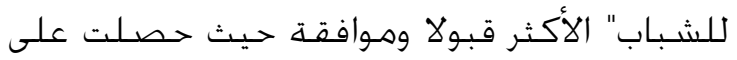

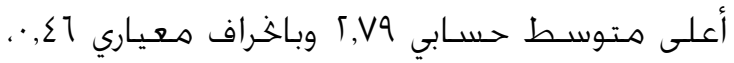

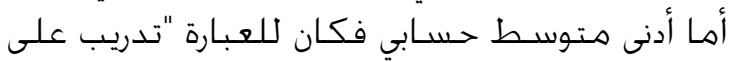

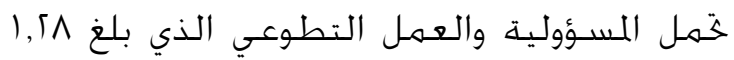

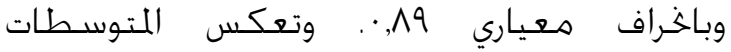
الخسابية إلى حــ كبير اتفاق وجهات نظيات نظر عينة

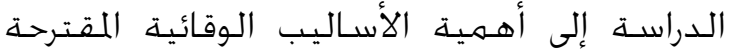

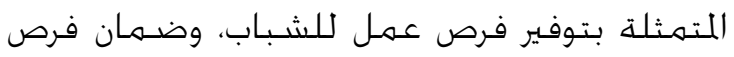

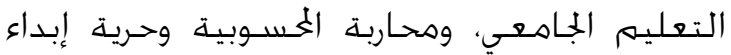

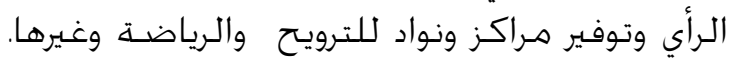

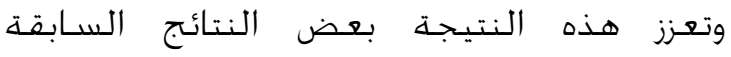

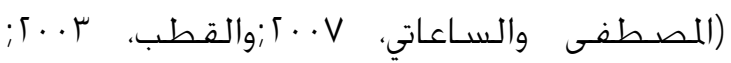
وهحهمود وسـلامـة، · (199).

كما تتفق نتائج الدراسـة هـع نتائج دراسـات

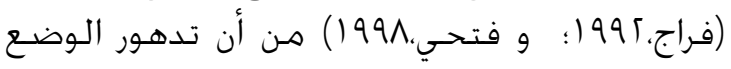

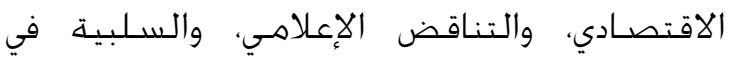

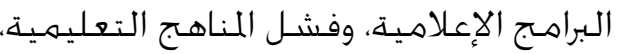




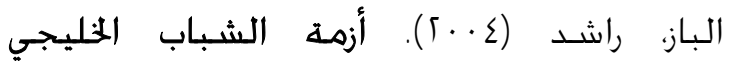

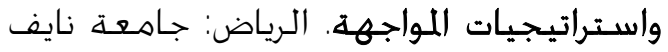
العربية للعلوم الأمنية.

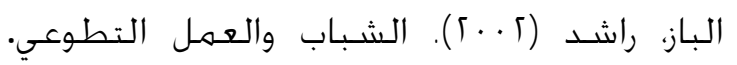

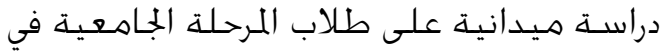

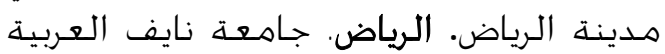

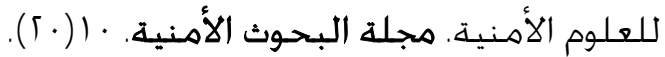
$. \Sigma T-i \mu$

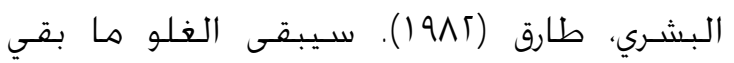

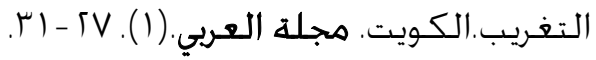

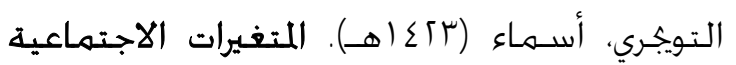

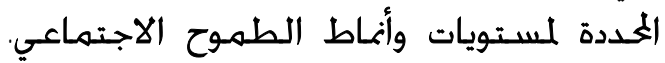
الرياض: مكتبة الملك عبد العزيز العامة.

أحسمد، عفراء (1997). مشكلات الشباب وكيفية

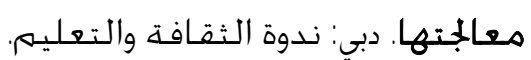

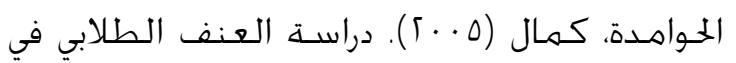

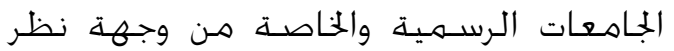

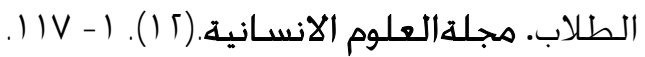

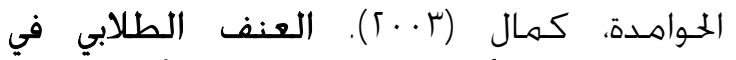

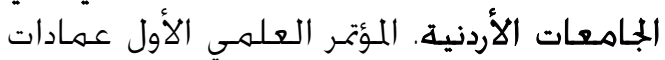

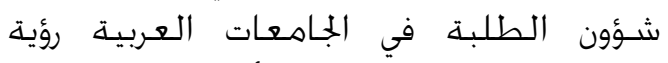
مستقبلية ،جامعة الزرقاء الأهلية. عـمان.

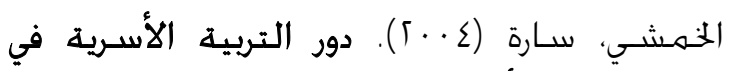

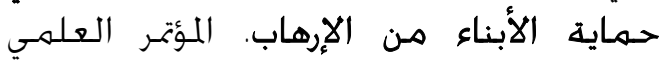
موقف الإسـام من الإبناء من الإرهاب. جامعة الأرئ الأمام

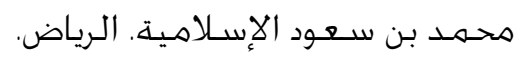

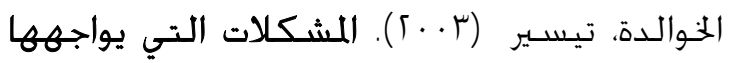

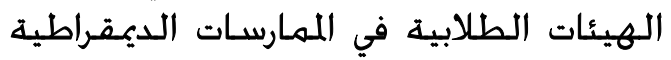

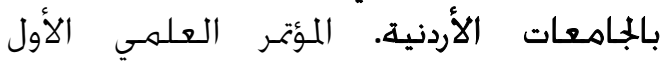

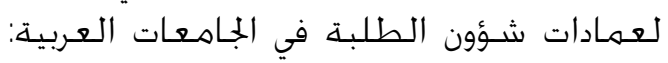
رؤية مستقبلية،جامعة الزرقاء الأهلية. عمان.

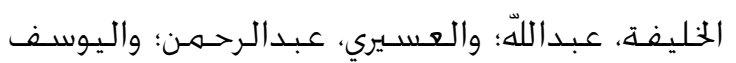

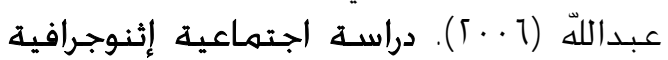

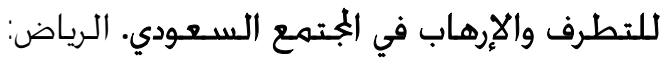

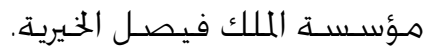
الجراية، أنور (1 (. ؟). المراهقة وعلاقته بأفراد الأسـرة

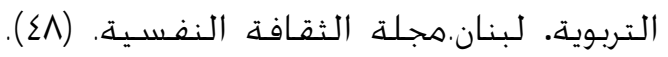
.10- $\varepsilon$

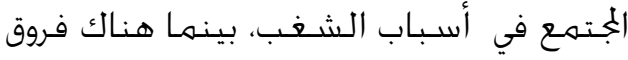

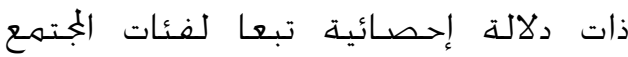

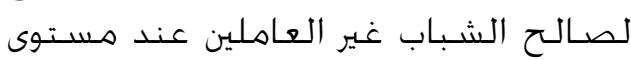

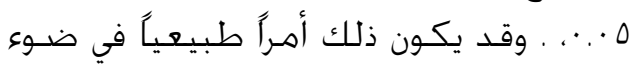

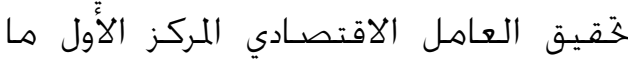

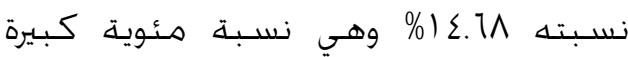
بالنسبة لعينة الدراسـة.

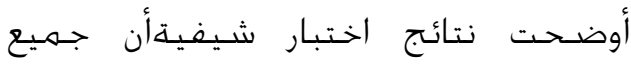
المقارنات الثنائية بين فئات عينة الدراسـة فئة

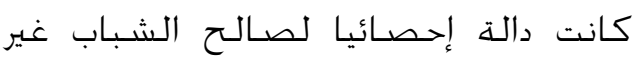

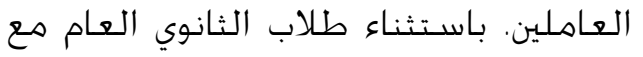
الجامعيينوالجامعيين مع الموظفين.

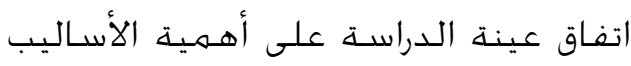

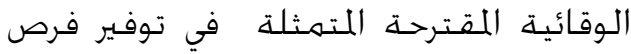

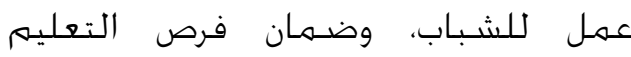
الجامعي، ومحاربة الخســوبية، وحـرية أبداء الرأي لئي

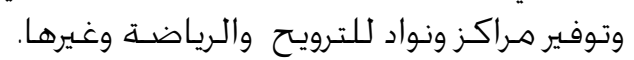

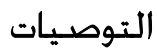

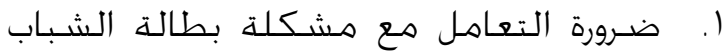

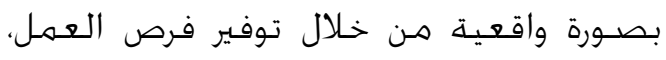

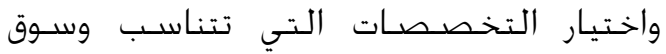

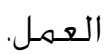

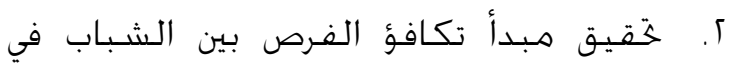

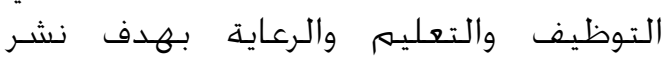
الاطمهئنان والعـدالة بينهم. والتهم.

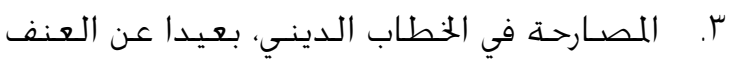

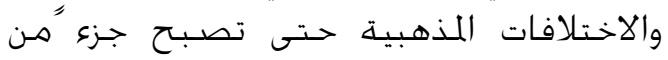
مارسـة حياة الشباب. ع. خلق مناخ للحـوار على كافة المستويات الأسـرية والاجتماعية والاقتصنادية والدينية.

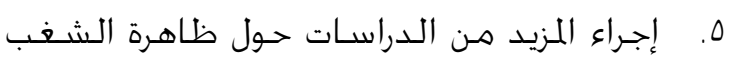

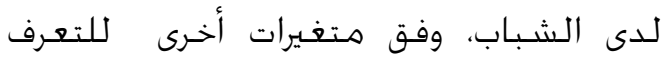
عليها والتعامل معها بواقعية.

\section{المراجع}

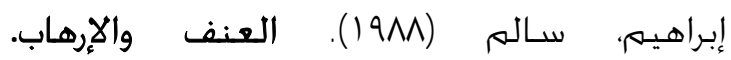

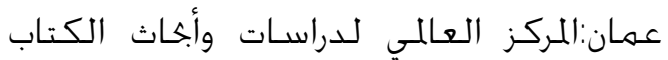
الأخضـر. المركز 
الثانوي بدولة الكويت. الكـويت ـ الجلة التربوية.

$$
\text { . } \varepsilon \cdot r \mu, \Sigma 1
$$

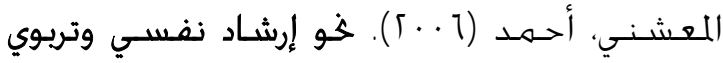
يساهم في تنمية الوعي بالذات لدى طلبة المئه

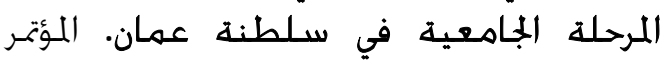

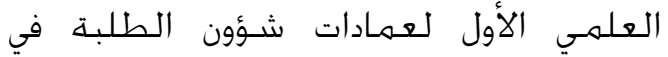
الجامعات العربية: رؤية هستقبلية. جامعة الأولية الزرقاء الأهلية، عمان. الجعان.

المصطفى، عبد العزيز؛ والسـاعاتي، عبد العزيز

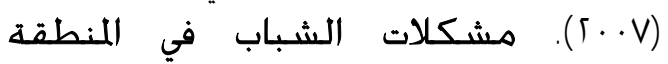

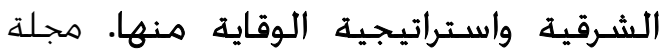

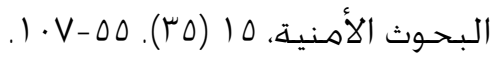

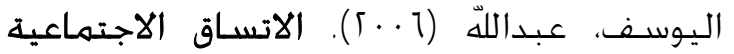

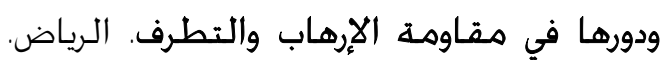
جامعة نايفالعربية للعلوم الأمنية.

اليوسـف، عبد اللهّ (ع · ؟). دور المدرسـة في مقاومة

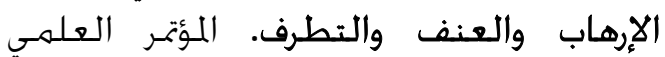

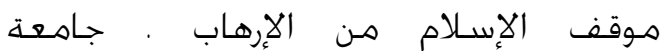

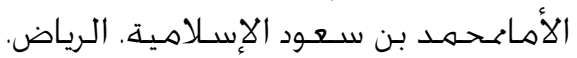

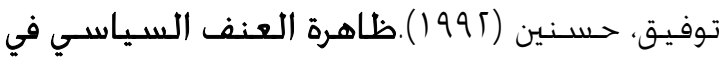

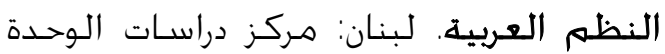
العربية.

حجازي، عزت (910) (1). الشباب العربي ومشكلاته.

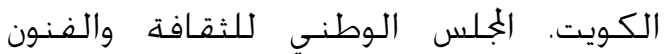

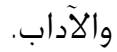

رزق، لطيفة (1991()). خو نظرة علمية لموقف التربية

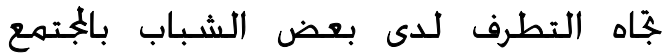

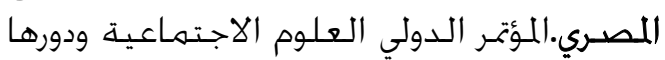

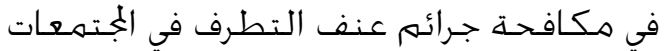
الإسـلامية. جامعة الأزهر. القـاهرة.

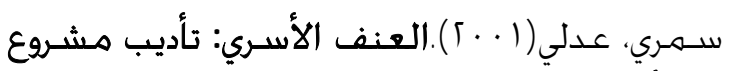

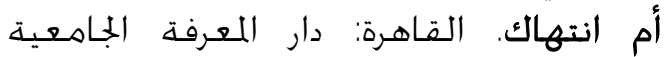
بالإسكندرية.

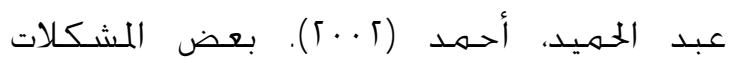

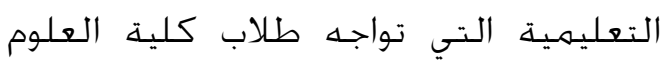

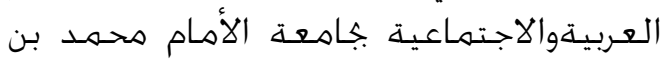

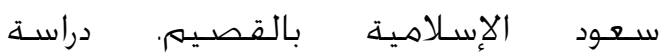

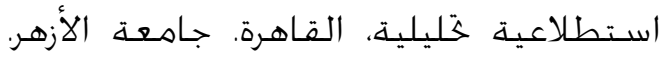
مجلة التربية، ك0، 00 -00.

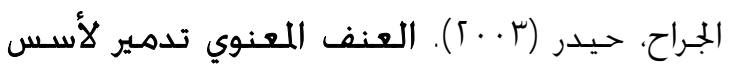
الحياة. لبنان. مـركزالدراسـات.أمان.

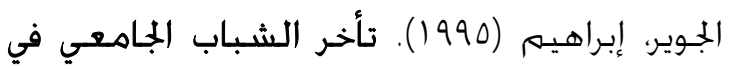

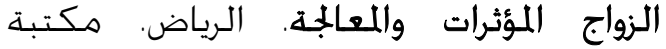

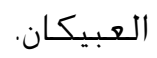

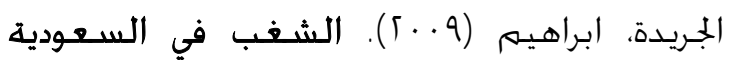

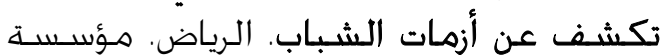
الملك فيصل الخيرية، السـورطي، يزيد (991)). السـلطوية في التربية العربية، المظاهر والأسـباب والنتائج.القاهرة. جامعة القـاهرة. الجملة التربوية. 1 (5 (). 0 ــ - 1.

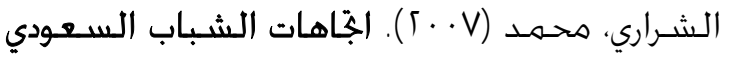
خو الإرهاب. (رسـالة دكتوراه غير منشـورة). الجامعة الأردنية، عمان، الأردن.

الطحيح، سـالم (911) (الشباب في الكـويت. جهاز

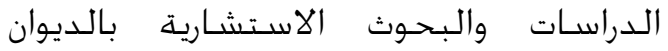
الأمسيري الكويتي. ارندت، حنة، (99V ()). العنف. بيروت: دار السـاقي.

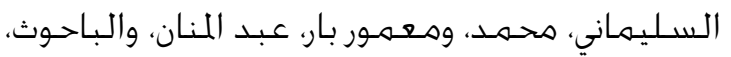

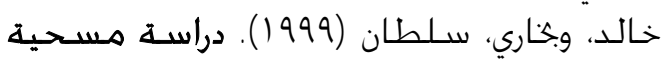

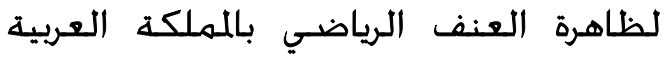
السعودية. الرياض.معهد إعداد القادة.

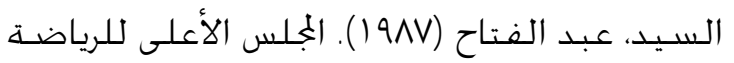

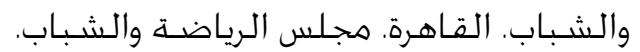

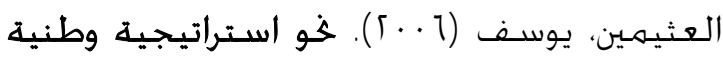
شاملة لكافحة الإرهاب في المملكة العربية

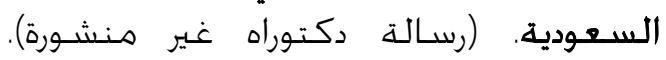
جامعة الامام محمد بن سـعود الاسـلامية.

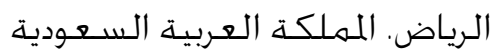

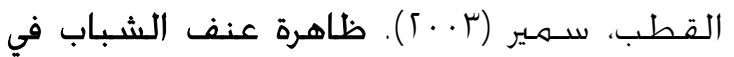

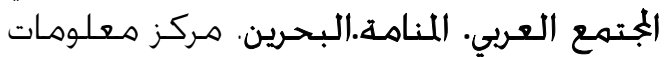
المرأة والطفيل. الطعري.

القوس، سـعود (9) (هـ). العواهل المرتبطة بالعنف

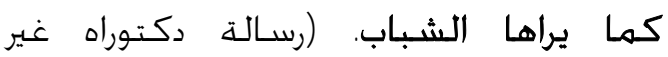

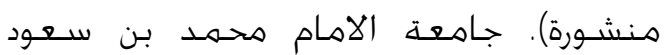

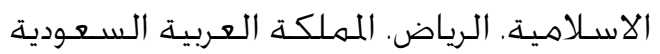

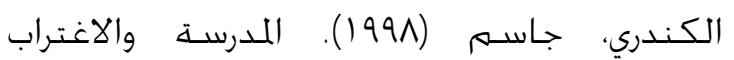
الاجتماعي: دراسـة ميدانية لطلاب التعليم 


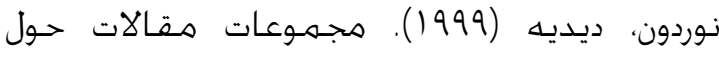

الشباب. فرنسـا. مجلة بور العلمية. 0 (أ. (). $.0 \Sigma-\Sigma 1$

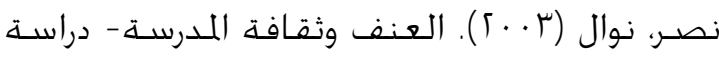

خليلية نقدية. القاهرة. مجلة التربية والتنمية. $\left.. V O-V \cdot(T)^{\prime}\right) \Gamma V$

وطفة، علي (^ . - ؟). العنف والعدوانية في التحليل

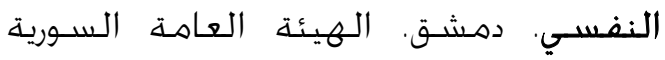
للكتاببوزارة الثقافة السـورية، سـوريا.

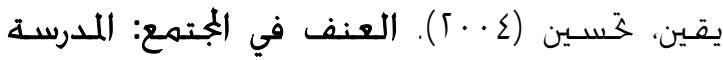
مثالا. لبنان.هركز دراسـاتأمان.

يس، السيد (1994). التقرير الاستراتيجي العربي

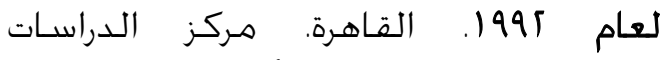
السياسـية والاستراتيجيبـالأهرام.

Candace, K., \& Moude, D. (1992). Will they tell? A ssessingpreadolescent, 29 (2), 136-140.

Dunning, E. (1994). The social roots of football hooliganism. In: R. Giulianotti (Ed.). Footballviolence and social identity (pp. 3444). London \& N ew York: Routledge.

Joram, M. (1993). The economics of violence. Dissertation A bstract, 53(7). 1456-1462.

Pittman, K., \& Cahill, M. (1991). A new vision: promoting youth development.Center for Youth Development and Policy Research. Washington DC: Academy for Educational Development.

Rashed, D. (1978). Violence and socioeconomic development.International Social Science Journal, 73(4), 234-245.

Solomon, M. (2000). The fruits of their labors: Longitudinal exploration of parent personalityand adjustment in their adult children. Journal of Personality, 68 (7), 280286.

Souzouk, S. (1983). A study of violence a many in junior high school. Research Quartely Excerscise Sport, 52 (7), 27-137.

Wurtz, A., \& Lomette, G. (1984). Researching of TV violence. Society, 21(6), 4-14.
عبد المختار، محمد (5 (99 ()). علاقة مشاهدة النماذج

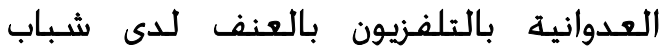

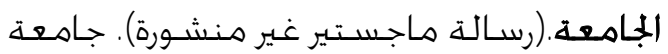
عين شـمس. القـاهرة. مصر.

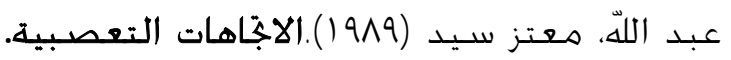

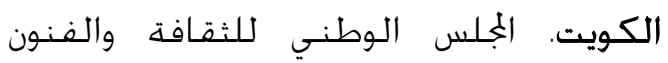

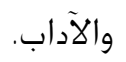

فتحي، عزة (991 (). دور التربية في مكافحة جرائم

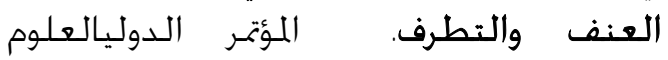

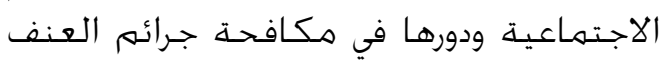

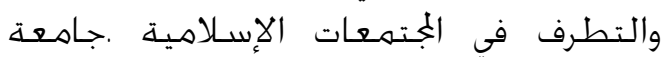
الأزهر. القعاهرة.

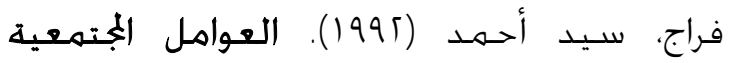
لظاهرة العنف بين طلبة الجامعات. (رسالة

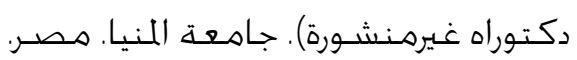

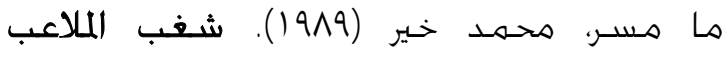

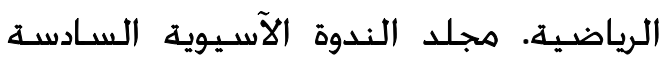

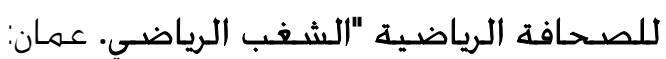
الاختاد الأردني للإعلام الرياضـي والشـبابي.

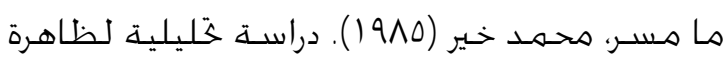

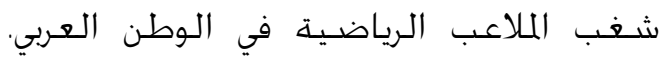

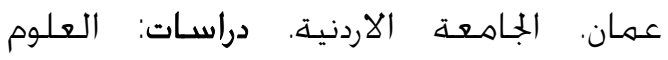

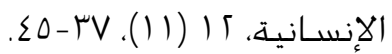

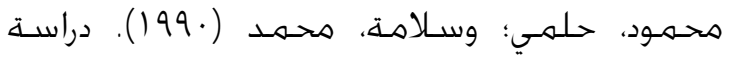

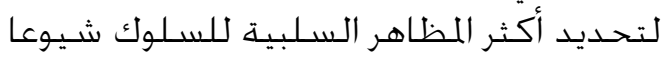

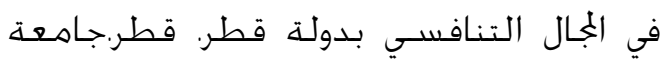

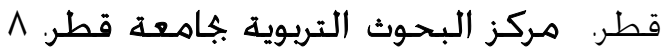
. $) \wedge \Gamma-I V \varepsilon .(1))$

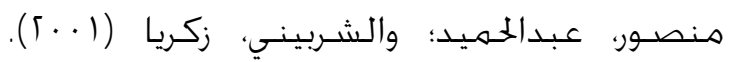

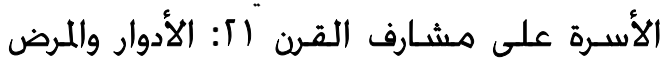

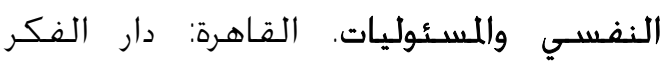
العربي. منظمة الأمهم المتحدة للتربية والعلوم والثقافة (الئة

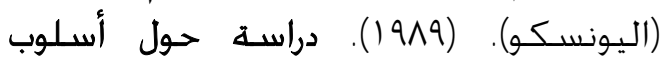

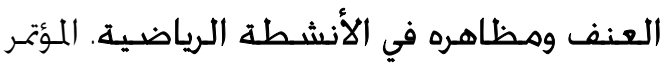

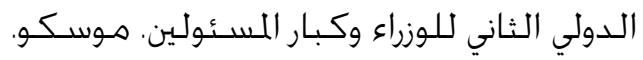




\section{(1) (لملحق \\ بسـم اللة الرحمـن الرحيم}

ظاهرة شـب الشباب والأسـاليب الوقائية بالمنطقة الشرقية من المملكة العربية السعودية

$$
\text { أخي الشـاب }
$$

السـلام عليكم ورحمة اللهّ وبركاته

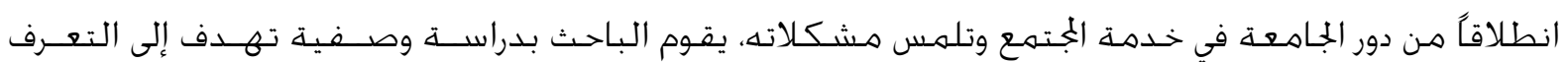

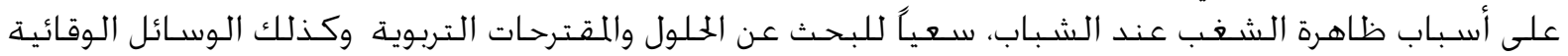

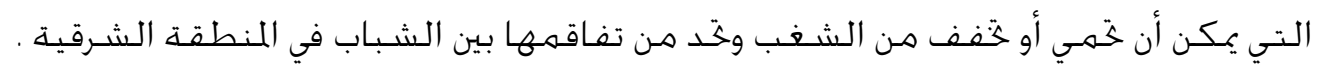

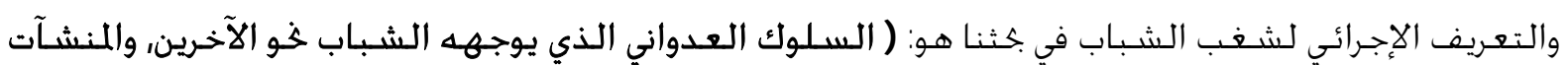

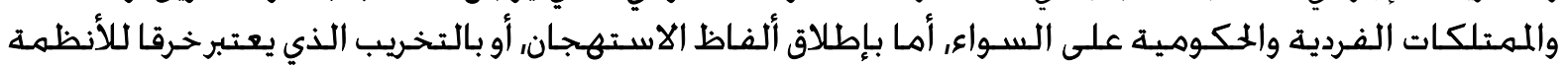

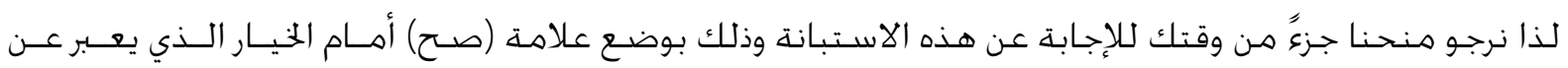

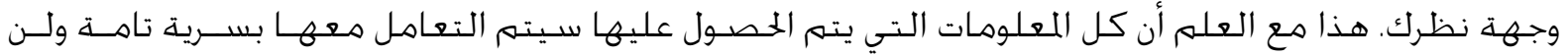

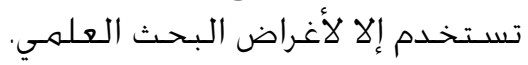

وجزاكم اللهّ خيرا

البيانات الأولية:

فضـلا ضـع علامة (ل) أمام المربع المناسب واملأ الفراغ بما يناسبـ:

$$
\begin{aligned}
& \text { العمر:(.......) } \\
& \text { المهنة: طالب | موظف |غير متعله: (................... } \\
& \text { نوع العمل |المهنة: (................ }
\end{aligned}
$$

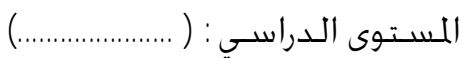

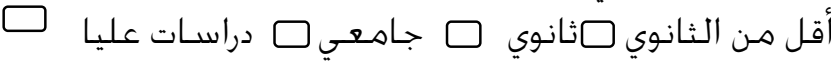

مكان السكن الحالي: (...............

المدينة |القرية |الهجهرة: (ل.................

بيانات تتعلق بالأسـرة:

\begin{tabular}{|c|c|c|c|c|}
\hline 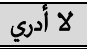 & $\gamma$ & نعم & العبارات & رقم \\
\hline & & & 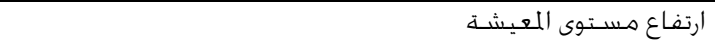 & .1 \\
\hline & & & ارتفـاع نسبـة البطالة بين الشـباب & ז \\
\hline & & & الخفـاض دخل الأســرة المادي & r \\
\hline & & & انتشـار العمالة الأجنبية متعددة الجنسـيات التي تتحكم في الوظائف &.$\Sigma$ \\
\hline & & & التفـاوت الكبـير في مســوى الدخـل بين الأســر & .0 \\
\hline
\end{tabular}

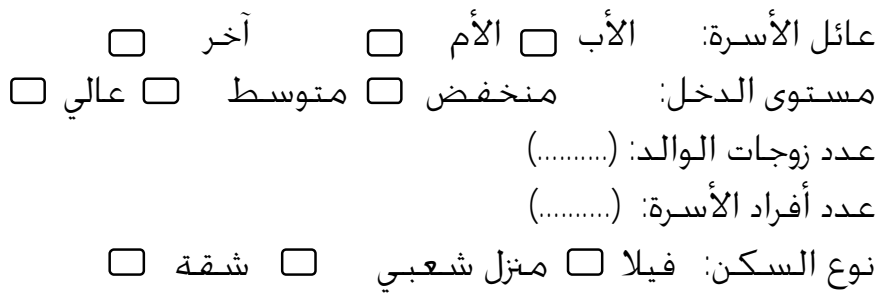

ثانيا: فضلا ضع علامة (ل) أمام الخيار الذي يعبر عن وجهة نظرك

المحور الأول : العامل الاقتصادي 


\begin{tabular}{|c|c|c|c|c|}
\hline لا أدري & $\gamma$ & نعم & 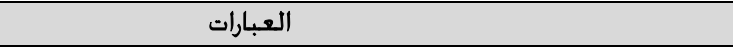 & رقه \\
\hline & & & عدم مناسبة التأهيل الجامعي لسـوق العـمل & 1. \\
\hline & & & عدم توفر الأمـن الوظيفي للشباب &.$v$ \\
\hline & & & مسـتوى دخل الشـباب لا يتناسب ومتطلبات الحياة اليومية & . \\
\hline & & & عدم تمكن الشباب من تلبية حاجاتهم الكمالية كالسـفـر أثناء الإجازات & .9 \\
\hline
\end{tabular}

الخهور الثاني : العامل الأسـري

\begin{tabular}{|c|c|c|c|c|}
\hline لا ل أدري & $\gamma$ & نعم & العبارات & رقم \\
\hline & & & التفكك الأسـري بين أفراد الأســرة & .1 \\
\hline & & & الشـــة الزائدة على الأبناء & . \\
\hline & & & التـليل الزائد للأبناء & r. \\
\hline & & & اشتغال أولياء الأمور عن متابعة وتقصي أحوال أبنائهـم &.$\varepsilon$ \\
\hline & & & غياب (القدوة الصـالحة) في الجُتمع الغيط بالأبناء & .0 \\
\hline
\end{tabular}

المحور الثالث : العامل الديني

\begin{tabular}{|c|c|c|c|c|}
\hline لا أدري & $\gamma$ & نعم (a) & 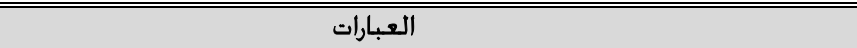 & رقيم \\
\hline & & & الخـافات المستـمرة بين الفقهاء والأئمة حول تناول بعض القضايا الحياتية & .1 \\
\hline & & & التطرف الديني الذي يدعو إلى رفض الآخرين & ז \\
\hline & & & ضعفف برامه التثقيف الديني & $r$ \\
\hline & & & استغلال الدين لخدمة مصـالح شـخصية &.$\varepsilon$ \\
\hline & & & جهود بعض رجال الدين في بعض القضـايا & .0 \\
\hline & & & انتشـار بعض الجماعات الشبابية المتطرفة دينيا & .1 \\
\hline & & & اجخاه الشباب إلى العنف الاجتماعي في حل مشاكلهـم & . \\
\hline & & & استغلال بعض طلبة العلم الشباب لإثارة العنف لتحقيق أهدافهم & $\wedge$ \\
\hline & & & عجز القائمين على المساجـد في تبنـي قضايا الشباب المعاصـرة & .9 \\
\hline & & & ضـعف الوازع الدينـي لدى الشـباب & .1 . \\
\hline & & & ضـعف دور المسـاجد في توجيه الشـباب وإرشادهم إسـلاميا بما يسـهل حل مشـاكلهـم & .11 \\
\hline
\end{tabular}

المحور الرابع : العامل الصحي /الترويحي

\begin{tabular}{|c|c|c|c|c|}
\hline ل الأدري & $\bar{\gamma}$ & نعم & العبارات & رقم \\
\hline & & & تعاطي الشباب المخــرات والمسكرات & .1 \\
\hline & & & ســوء اســـلال وقت الفـراغ عنـــ الشبـاب &.$\Gamma$ \\
\hline & & & الافتقار إلى برامج ترويخية تستثمر طاقات الشباب & $r$ \\
\hline & & & عدم توفر أماكن الترفيه والترويح العامة للشبـاب & $\varepsilon$ \\
\hline & & & الغخالاة في التعبير عن الفوز والخسـارة الرياضي & .0 \\
\hline & & & اللجهوء إلى أسـاليب العنف في التشـجيع الرياضي & .1 \\
\hline & & & التأثير السـريع من الأفكار المنحرفة التي تعرض عبر وسائل الإعلام المختلفة &.$v$ \\
\hline & & & قيادة السيارة بسـرعة جنونية & $\wedge$ \\
\hline & & & مشـاهدة التفحيط & .9 \\
\hline & & & سـهولة التقاء الشباب عبر الانترنت & .1 . \\
\hline & & & سـوء التغذية العامة لقطاع كبير الشباب & .11 \\
\hline & & & الافتقار إلى المؤسـسـات العـاجية والنفسية. & .11 \\
\hline
\end{tabular}

المهور الخامس : العامل الاجتماعي

\begin{tabular}{|c|c|c|c|c|}
\hline لا ل أدري & $\gamma$ & نعم & العبارات & رقهم \\
\hline & & & الشـعور بالعجز من عدم خَقيق الشباب أهدافهم بدون واسـطة & .1 \\
\hline & & & عدم احترام الشباب العادات والتقاليد الاجتماعية & .1 \\
\hline & & & الشـعور بعدم العـدالة الاجتماعية & r \\
\hline & & & سـوء التكبف الاجتهماعي داخل الجُتمع &.$\varepsilon$ \\
\hline & & & كثرة معاكسـات الشباب للجنس الآخر & .0 \\
\hline
\end{tabular}




\begin{tabular}{|c|c|c|c|c|}
\hline لا أدري & $\gamma$ & نعم & 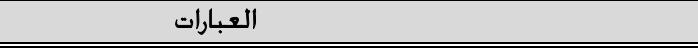 & رقم \\
\hline & & & تقليد الحياة الغربية بصـورة عمياء & .1 \\
\hline & & & الشعـور بالاغتراب الاجتـماعي &. $\mathrm{V}$ \\
\hline & & & اقتداء الشـباب بالمشـاهير في لبسهـم وسـلوكهم &.$\wedge$ \\
\hline & & & استثارة البرامج الإعلامية العنف لدى الشباب & .9 \\
\hline & & & الهجرات المكثفة للشباب من الريف للمدينة & .1 . \\
\hline & & & الصـراعات الطائفية لوجود بعض الأقليات وإحساسـهم بالاضطهاد & .11 \\
\hline & & & الخروج السـافر على العادات والتقاليد والأعراف الاجتماعية & .15 \\
\hline
\end{tabular}

المحور السادس : الأساليب الوقائية المقترحة للتصدي للشغب

\begin{tabular}{|c|c|c|c|c|}
\hline لأدري & $\gamma$ & نعم & 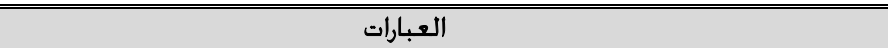 & رقم \\
\hline & & & توفير فرص عمـل للشـباب & .1 \\
\hline & & & توفير فرص حرية إبداء الرأي للشبـاب &.$\Gamma$ \\
\hline & & & توفير نواد رياضية واجتماعية وثقافية جاذبة مجانية للشباب تستثمر طاقاتهم وتنمي & $r$ \\
\hline & & & تبني الأئمة والخطباء خطابا توجيهيا للشباب & 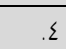 \\
\hline & & & ضـمان فرص التعليم الجامعي للشباب & .0 \\
\hline & & & مكافــة المسكرات والمخدرات بأنواعها المختلفة & .1 \\
\hline & & & رعاية الفقراء والعتاجين من الشباب & . $\mathrm{V}$ \\
\hline & & & تيسـير سـبل الزواج للشباب لضـمـان اسـقـرارهم النفسـي & $\Lambda$ \\
\hline & & & تشـجيع الأنشـطـة الطلابية الداعمة لأسـاليب المحوار واحترام الآخرين & .9 \\
\hline & & & محاربة المُسوبية والماباة فيما يتعلق بقضايا الشباب & .1 . \\
\hline & & & تدريب الشباب على خَمل المسئولية والعمل التطوعي & .11 \\
\hline & & & بثث القيم الإسـلامية في نفوس الشباب مـن خلال براهج التعليم والإعلام & .11 \\
\hline & & & المواءمة بين خُصـصـات التعليم العالي وحاجات سـوق العمل & .14 \\
\hline & & & التثقيف الأســري وتعزيز دورا لأسـرة في تربية وتوجيه الأبناء & $.1 \varepsilon$ \\
\hline & & & وضـع استراتيجية وطنية للإعلام لتفادي اخخرافات الشباب & .10 \\
\hline & & & إنشـاء مواقع متخصصـة في الإنترنت للتصـدي للشباب الذين يمارسـون الشغب & .11 \\
\hline & & & عمل برامج تلفزيونية توعوية لتعريف الشباب بخطر الشغب &. $\mathrm{IV}$ \\
\hline & & & تَسـين فرص استـــرار الشباب مواصلة تعليمهـم العالي & $.1 \Lambda$ \\
\hline & & & مراقبة المواقع الالكترونية والمنتديات الفكرية الني تدعو إلى التطرف والغلو & .19 \\
\hline & & & تفعيل جماعة الحي ودعمها وتشجيعها &.$\Gamma$ \\
\hline
\end{tabular}

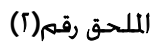

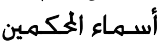

\begin{tabular}{|c|c|c|c|c|}
\hline ملاحظات & القســم & الكلية & الاسـم & p \\
\hline & قسـم التربية وعلم النفس & التربية & أ.د. مـدوح صـابر & 1 \\
\hline & قسـم التربية وعلم النفس & التربية & أ.د. حسـن علام & 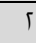 \\
\hline & قسـم التربية وعلم النفس & التربية & د. عادل بن سـعد بودلي & $r$ \\
\hline & قســـم الدراسـات الإسـلامية & التربية & د. بسـام العطاوي & $\varepsilon$ \\
\hline & قسـم التربية وعلم النفس & التربية & أ. سـالم أبو غنمي & 0 \\
\hline
\end{tabular}

